\title{
El Poder Episcopal en la Diócesis de Cuenca durante la Edad Media
}

\author{
JORGE DIAZ IBÁÑEZ \\ Universidad Complutense de Madrid
}

Dentro del conjunto de poderes que desempeñaron un papel más relevante en el desarrollo y evolución histórica de la sociedad castellana a lo largo de las últimas centurias del Medievo, un ámbito de estudio esencial a tener muy en cuenta, dada su enorme trascendencia, es el del poder ejercido por la Iglesia, y dentro de ésta por el Episcopado en particular. Ello es algo que ha sido puesto sobradamente en evidencia por la historiografía más reciente.

Conquistada Cuenca por Alfonso VIII en 1177 y fundada una nueva diócesis con sede en esta ciudad en 1182, durante la Edad Media la titularidad de la mitra sería ostentada por un total de 31 prelados cuya potestad se proyectó en un doble ámbito. Por un lado, este poder de los obispos se manifestó intraeclesialmente dentro de la propia diócesis, afectando tanto al conjunto del clero como a los laicos. Por otra parte, además, la potestad episcopal también tuvo un fuerte grado de proyección sociopolítica a través del mantenimiento de todo un complejo y variado sistema de relaciones de poder con otras instituciones y grupos sociales, lo que constituye por sí una temática demasiado amplia como para que pueda quedar recogida en este artículo de modestas dimensiones.

Por ello, el objeto del presente trabajo consistirá en estudiar sólo la primera de ambas facetas del poder episcopal conquense, la intraeclesial, lo que permitirá apreciar de qué modo se manifestaba a nivel local, dentro de un obispado, dicha potestad eclesiástica ejercida por el titular de la mitra.

\section{LAS ELECCIONES EPISCOPALES}

Antes de pasar a hablar sobre la caracterización general del poder episcopal conquense, resulta imprescindible establecer una valoración 
global sobre la eiección de los obispos de Cuenca durante la Edad Media. Tal como se acaba de señalar, durante las centurias medievales la sede episcopal conquense fue ocupada por un total de 31 prelados, desde don Juan Yáñez, primer obispo, que ya figura como electo en 1178, hasta el absentista don Rafael Riario, cardenal de San Jorge, que ostentaría la titularidad de la mitra conquense entre 1493 y 1518 . Los factores y circunstancias que incidieron directa o indirectamente en la designación de todos estos prelados fueron de lo más diversos $y$, junto a motivaciones estrictamente eclesiásticas, la mayoría de las veces serán mucho más determinantes factores de carácter político y social que deben ponerse muy en relación con la propia dinámica evolutiva de la Iglesia occidental y con el desarrollo histórico de la Realeza y sociedad castellana. Así, en la elección de los obispos de Cuenca durante la Edad Media, junto al escaso papel que en la práctica desempeñó inicialmente el cabildo catedralicio, fue mucho más determinante el que jugaron la Monarquía castellana, el Papado y en ocasiones los arzobispos de Toledo.

En el canon 24 del IV Concilio de Letrán se establecieron claramente las tres formas básicas de elección del obispo por el cabildo catedralicio: "quasi per inspirationem", por sufragio de la "maior vel senior pars" y mediante el sistema de compromisarios. A su vez, en Castilla las Partidas también se harían eco de toda esta tradición legislativa de origen conciliar sobre el papel desempeñado en las elecciones episcopales por los cabildos catedralicios y sobre los tres tipos de elección arriba mencionados ${ }^{1}$. Una vez que dicha elección era llevada a cabo dentro de un plazo máximo de tres meses desde la muerte del obispo anterior, tal como establecía el Derecho Canónico, el paso siguiente era la aceptación por el electo y por el metropolitano de Toledo, procediéndose después a su consagración y, si se daba el caso, a la correspondiente confirmación pontificia.

Las únicas elecciones efectivas teóricamente realizadas por el cabildo catedralicio conquense sobre las que nos ha quedado constancia documental fueron las de don Pedro Lorenzo en 1261, don Gonzalo Pérez Gudiel en 1273, don Gonzalo García Gudiel en 1280 y don Gonzalo Díaz Palomeque en 1289. En todos estos casos el sistema elegido fue el de compromisarios, pero al tratarse de personajes muy vinculados a la Monarquía castellana es más que probable una intromisión de esta última en el proceso electoral. A su vez todos ellos, excepto don Pedro Lorenzo, previamente a su elección ya ostentaban dignidades en el propio cabildo

1 Partidas, I, V, XVII-XXI. 
catedralicio conquense. A lo dicho antes podrian añadirse las elecciones fallidas del deán de Cuenca Pedro Martínez, por renuncia de éste, en 1322; del noble conquense Gil Álvarez de Albornoz, futuro cardenal que entonces era arcediano de Huete, en 1326 y 1327, a cuya elección por el cabildo catedralicio se opuso en ambas ocasiones Juan XXII aludiendo razones de defecto de edad y órdenes; y la del también noble conquense Juan Hurtado de Mendoza, realizada a instancias del concejo de Cuenca en 1469 , y a la que también el papa se opuso tajantemente.

Así, por tanto, las elecciones llevadas a cabo por el cabildo catedralicio fueron pocas si se tiene en Cuenca que fueron un total de 31 obispos los que ostentaron la titularidad de la mitra conquense durante los siglos medievales. Además, en todos los casos citados, tal como se ha dicho, es probable una intromisión de la Monarquía castellana, así como del arzobispo de Toledo, pues los Gudiel y los Palomeque eran familias de mozárabes toledanos muy vinculadas a la mitra arzobispal y a su cabildo catedralicio. Además, en ningún caso fueron elegidos prelados pertenecientes a familias de la nobleza conquense, debiendo llamarse la atención sobre los esfuerzos que en vano realizaría el cabildo para intentar lograr esto último, que finalmente no se conseguiria debido a la oposición pontificia.

Respecto a la intervención directa o indirecta del arzobispo de Toledo en la elección de los obispos de Cuenca, puede decirse que parece muy probable fundamentalmente durante los siglos XII y XIII, pues en esta época casi todos los prelados conquenses procedían de familias mozárabes toledanas muy vinculadas a la sede arzobispal. Así, a los casos ya citados, cabría añadir los de don Juan Yáñez, electo de Cuenca en 1178 y hasta entonces arcediano de Calatrava en la Iglesia de Toledo; San Julián, obispo de Cuenca desde 1197 y hasta ese momento también arcediano de Calatrava; don García Ruiz, electo conquense a fines de 1208; don Lope Ruiz, elegido como obispo en 1225; y don Gonzalo Juanes, obispo de Cuenca al menos desde 1231. Durante los siglos XIV y XV, en cambio, los prelados conquenses dejarán de proceder de estas familias de mozárabes y el grado de intromisión de los arzobispos de Toledo en su elección será casi inexistente, dejando paso a un mayor afianzamiento de la voluntad pontificia, aunque en el caso de don Bernardo Zafón, elegido como obispo de Cuenca en 1362, quizá pueda sospecharse un cierto influjo de Toledo por haber ejercido hasta entonces el cargo de tesorero en el cabildo toledano.

La provisiones pontificias también son otro factor a tener en cuenta, aunque en este caso es muy importante discernir sobre la base de diversos indicios entre las elecciones llevadas a cabo por iniciativa del propio 
pontífice y aquellas otras en las que el papa se está limitando a elegir a un candidato previamente propuesto por el rey a través de alguna súplica. Con todo, de un total de 21 casos de provisiones episcopales realizadas por el papa durante la Edad Media, de las cuales casi todas corresponden a los siglos XIV y XV, la existencia de una clara iniciativa por parte del pontífice puede señalarse al menos para las elecciones de don Mateo Reinal (1247), Fray Esteban (1322), Antonio Jacobo de Veneris (1469) y el cardenal Rafael Riario (1493), dándose también otros casos en que el nombramiento se realizó tanto por iniciativa pontificia como regia. Lo que si que resulta evidente es que la centralización aviñonesa tuvo una clara incidencia en la diócesis conquense, pues a partir del siglo XIV el cabildo catedralicio dejaria de desempeñar el, aunque teórico, pequeño papel que hasta entonces habia jugado en las elecciones episcopales.

Pero fue sin duda la Monarquía castellana la institución que más influyó en la elección de los obispos conquenses a lo largo de toda la Edad Media, ya desde el mismo momento de la fundación del obispado, a fines del siglo XII, hasta fines del XV. Durante los siglos XII y XIII la elección de casi todos los obispos de Cuenca estuvo manipulada por la Monarquía, bien dando a conocer el parecer regio en las elecciones realizadas por el cabildo catedralicio, o bien a través de otro tipo de medios. Durante los siglos XIV y XV, en cambio, la Realeza castellana tendría que compartir su protagonismo en los procesos electorales con el desempeñado por el papa, pues si bien en muchas ocasiones el pontífice eligió al candidato propuesto por el monarcá, tampoco faltaron algunos casos en que la iniciativa electoral partió fundamentalmente del papa. Por lo que respecta a la diócesis de Cuenca, el más claro ejemplo de este choque de intereses Monarquía-Papado, por lo demás muy característico de casi todos los reinos occidentales durante el siglo XV, lo tendremos en la pugna que se suscitó entre 1479 y 1482 entre el papa Sixto IV y los Reyes Católicos por la provisión de la sede conquense, de la cual saldrían finalmente triunfantes los monarcas al serle entregada la mitra a su candidato Fray Alonso de Burgos. Todo ello, en definitiva, pone de relieve que durante estos siglos la Monarquía trató de ejercer un control creciente sobre los obispos de Cuenca, pues era consciente de la enorme carga política que revestía el Episcopado y por ello le convenía que los ocupantes de las sedes fuesen personas de su confianza.

Al tomar posesión de su cargo todos los obispos de Cuenca, al igual que sucedía con las dignidades y canónigos, debian jurar los Estatutos de la Iglesia conquense, siéndoles tomado frecuentemente el juramento por el deán. 
En lo que respecta a la extracción social del Episcopado conquense durante la Edad Media, de forma general cabe señalar que durante los siglos XII y XIII casi todos procedian de algunas de las principales familias de mozárabes toledanos, mientras que en las dos centurias siguientes, exceptuando los casos de obispos extranjeros ${ }^{2}$, procederán fundamentalmente de la mediana nobleza de diversos lugares de Castilla, pero no de Cuenca, pues sobre todos aquellos casos en que el origen geográfico nos es conocido no tenemos constancia de ningún obispo de origen local, y ello fue debido fundamentalmente a la poca iniciativa electoral del cabildo catedralicio conquense, que a pesar de haber abogado en ocasiones a favor de algún miembro de los linajes más conspicuos de la ciudad, como eran los Albornoz y los Hurtado de Mendoza, nunca conseguiría su propósito al impedírselo los intereses pontificios o monárquicos que apuntaban en otra dirección.

\section{LOS PODERES GENERALES DEL OBISPO}

La máxima autoridad eclesiástica dentro de una diócesis es la representada por el obispo, y dicha autoridad tradicionalmente se ha subdividido en tres poderes: poder de orden, poder de magisterio y poder de jurisdicción.

En lo que respecta al poder de orden, una característica general para todo Occidente, y también constatable en Cuenca, es que el obispo es el único que puede administrar todos los sacramentos de la Iglesia. En su nombre algunos sacramentos son administrados por presbíteros, pero la confirmación y el orden sacerdotal le están reservados en exclusiva. Además el obispo tiene poder para ordenar la liturgia, aún cuando deba moverse en los marcos del ritual romano y de la tradición local. Fija las festividades del calendario litúrgico, consagra los santos óleos, las iglesias, altares, cálices y patenas, verifica las reliquias y bendice y acepta a los abades y abadesas. Podia tener bajo su jurisdicción ordinaria diversos ins. titutos religiosos como monasterios, beaterios, capillas y hospitales, que con el tiempo podían conseguir la exención al entrar en directa dependencia de una orden religiosa exenta. Cuando un obispo se ausentaba durante demasiado tiempo de su diócesis solía ser necesario el nombramiento de

\footnotetext{
2 Los tres prelados extranjeros que ocuparon la sede conquense fueron Fray Esteban (13221326), natural de Portugal, Antonio Jacobo de Veneris (1469-1479), natural de Italia, y Rafael Riario (1493-1518), también de origen italiano.
} 
un obispo auxiliar que, aunque no ostentaba la titularidad de la sede, se encargaba de ejercer provisionalmente los deberes episcopales vinculados a este poder de orden durante la ausencia del titular de la mitra. Por lo que respecta a Cuenca, la presencia de esta figura del obispo auxiliar aparece documentada al menos para el siglo $x \mathrm{~V}^{3}$.

Su poder de magisterio convierte al obispo en el responsable de toda la vida intelectual de la diócesis. Debe velar en primer lugar por la formación cultural de los clérigos, sobre todo de aquellos que tienen a su cargo la cura de almas. Por otra parte, la instrucción de los laicos a través de la catequesis, la predicación y la escuela está bajo su responsabilidad. Todos estos aspectos son recogidos profusamente por los sínodos conquenses bajomedievales, de los que se hablará algunas páginas más adelante.

En cuanto al poder de jurisdicción, al obispo corresponde dentro de su diócesis el otorgamiento de leyes y estatutos, sinodales o no, sobre diversos asuntos relacionados con el Derecho Canónico y el gobierno de la diócesis. De ello se deriva el derecho de la justicia episcopal a intervenir sobre esos mismos asuntos emitiendo sentencias y castigando a los culpables con penas espirituales y temporales de mayor o menor dureza según la gravedad de la falta cometida. El obispo administraba justicia mediante sus propios tribunales, personalmente 0 , como fue lo más común, a través de sus vicarios generales a los que transfería el poder jurisdiccional. A sus tribunales acudian las causas contenidas en la legislación episcopal en primera instancia o en apelación, y las sentencias dictadas, a su vez, podian ser apelables ante el tribunal metropolitano o pontificio. De esta potestad jurisdiccional también se derivaban algunos derechos del obispo, tales como procuraciones de visita, el llamado impuesto del catedrático ${ }^{4}$ y la luctuosa. Finalmente, como administrador y

3 El 23 de febrero de 1416 don Diego de Anaya, obispo de Cuenca, se dirigió a través de un comlinicado al cabildo catedralicio y a toda la clerecía secular y regular de su diócesis, así como a todos los laicos de la misma, informándoles de que, por estar él ocupado en diversos negocios al servicio del rey y no poder hacer frente a sus deberes episcopales, había pedido al obispo don Fray Manuel que acudiese a la diócesis de Cuenca para residir en ella por algún tiempo y cumplir en su nombre ciertos deberes episcopales como eran la confirmación de los fieles cristianos, consagración y bendición de abades y abadesas, consagración de altares e iglesias, etc. Don Diego ya habia dado a dicho obispo auxiliar licencia para todo ello, por lo que mandó que se le auxiliase con todo lo necesario para facilitarle el cumplimiento de su ministerio, dándole posada donde residir y todos los ornamentos y libros litúrgicos que necesitase. De este modo, el 5 de marzo de dicho año el obispo Fray Manuel se presentó en la catedral conquense con la mencionada carta por la que don Diego de Anaya le nombraba obispo auxiliar, y tras procederse a su lectura ante el cabildo catedralicio, éste prometió cumplir todo lo establecido en ella. Archivo Catedralicio de Cuenca (ACC), Actas Capitulares de 1416, f. 124v.

4 Se trata de una capitación fiscal de gran valor simbólico que entregaban al obispo los clé- 
gobernador de su diócesis, el obispo supervisa la organización material y beneficial; erige, divide y delimita las parroquias, autorizando su construcción o demolición; interviene junto con el cabildo catedralicio en la colación de beneficios ${ }^{5} \mathrm{y}$, en última instancia, bajo su responsabilidad se encuentra la correcta conservación de los bienes eclesiásticos de la diócesis.

\section{EL PODER JURISDICCIONAL DE LOS OBISPOS DE CUENCA}

\section{Caracterización de la jurisdicción episcopal}

La máxima autoridad eclesiástica en la diócesis de Cuenca era la representada por la institución episcopal, dado que los otros niveles de jurisdicción eclesiástica que había en la diócesis dependían en última instancia de la ejercida por el prelado. Ya desde fines del siglo XII, para el gobierno de la diócesis, los obispos de Cuenca legislaron a través de diversos "estatutos" o "constituciones", que desde mediados del siglo XIV serán promulgadas fundamentalmente, aunque no siempre, a través de los sínodos diocesanos. De esta potestad legislativa del obispo, que en líneas generales debía amoldarse a la normativa del Derecho Canónico, se derivaba su derecho a intervenir en todos los asuntos que eran regulados por dichas leyes, emitiendo sentencias y castigando a los culpables con penas tanto temporales como espirituales cuya aplicación estaba regulada en las constituciones, y cuya importancia variaba en función de la gravedad de la falta cometida.

rigos diocesanos en señal de sujección a su jurisdicción, y cuyo pago era condición indispensable para que la jurisdicción eclesiástica impidiera cualquier intromisión de la justicia secular en delitos cometidos por clérigos y otorgarse su protección a éstos.

5 Un interesante testimonio sobre la potestad que tenian lo obispos de Cuenca en materia beneficial es el que queda recogido en una carta de poder que el 6 de noviembre de 1416 otorgó el obispo don Diego de Anaya a su vicario general, Juan Alfonso, en la cual se señalan las facultades que éste tendría, en nombre del obispo, con relación a la colación de beneficios: otorgar cualquier beneficio que quedase vacante en el obispado, incluidas las dignidades y otros beneficios de la catedral, aunque la colación de canonjias, raciones y mediasrraciones en la catedral habria de hacerse conjuntamente con el cabildo; recibir renuncias de cualquier beneficio, haciendo luego colación de ellos a otras personas; anejar un beneficio a otro si sus rentas individualizadas no fuesen suficientes para mantener a una persona, asi como dividir beneficios cuyas rentas sean excesivas. ACC, Actas Capitulares de 1418, f. 186r. El 19 de octubre de 1420, haciendo uso de esta facultad, y por citar un ejemplo, el vicario general Juan Alfonso haría colación de una capellanía instituida en la parroquia de La Trinidad de Huete, que fue otorgada en favor de un tal Pedro Ferrández. ACC, Actas Capitulares de 1420, f. $111 \mathrm{v}$. 
Los obispos de Cuenca, al igual que sucedía en casi todas las diócesis, administraron justicia fundamentaimente a través de su vicario o vicarios generales, en los cuales delegaban su jurisdicción, y muy raras veces lo hicieron personalmente. El vicario general normalmente solía ser algún canónigo muy próximo al obispo, y en ocasiones podía incluso subdelegar el ejercicio de la justicia en un lugarteniente que actuase en su nombre.

En un nivel inferior a la del vicario general se encontraba la potestad jurisdiccional ejercida por el deán y los arcedianos, asi como por los arciprestes y vicarios rurales y sus respectivos lugartenientes. No obstante, tal como ya dejó bien claro el obispo don Juan Cabeza de Vaca en el sínodo de 1399, los arciprestes y vicarios rurales sólo podían actuar sobre causas de carácter menor, dado que la potestad jurisdiccional sobre todas las causas criminales, civiles, matrimoniales, beneficiales y mixtas en todo el territorio diocesano estaba reservada en exclusiva al obispo o su vicario general ${ }^{6}$. En el sínodo de 1446 Fray Lope de Barrientos reiteraría esta medida, estableciendo además que cuando dichos arciprestes y vicarios administren justicia lo hagan siempre en las poblaciones cabeza de sus respectivos arciprestazgos y vicarías 7 , y prohibiéndoseles dar licencias de enterramiento dentro de las iglesias o para hacer cualquier tipo de obra o cambio en ellas, dado que el otorgamiento de dichas licencias estaba reservado en exclusiva al obispo ${ }^{8}$. De todas formas, en última instancia, la jurisdicción que ejercían los arciprestes y vicarios rurales para causas menores siempre estaba supeditada a la jurisdicción episcopal, y ya en el siglo XVI incluso se llegaría a poner en duda el que pudiesen tener de derecho algún tipo de potestad jurisdiccional, que en la práctica sí que poseían ${ }^{9}$.

ACC, Libro de Estatutos (Secretaria, n. ${ }^{\circ} 410$ ), f. $34 \mathrm{r}$.

Constituciones sinodales de 1446, promulgadas por el obispo de Cuenca Fray Lope de Barrientos, Biblioteca del Colegio de Santa Cruz de Valladolid, Ms. 340, ff. $7 \mathrm{v}-8 \mathrm{r}$.

lbid., f. $19 \mathrm{v}$.

En las constituciones sinodales de 1531 don Diego Ramírez de Villaescusa negará que los ocho arciprestes rurales del obispado tengan de derecho jurisdicción alguna, especificando que si la tuviesen es poque la ganaron clandestinamente. En función de elło don Diego establece que, si se demostrase que algún arcipreste posee de derecho algún tipo de potestad jurisdiccional, jamás deberá entrometerse en causas criminales, beneficiales, matrimoniales ni decimales, dado que según todas las constituciones anteriores estas causas están reservadas en exclusiva al obispo. Respecto a la jurisdicción de los vicarios rurales, señala que éstos habrán de demostrar si efectivamente la poseen para ciertos asuntos menores, en cuyo caso se les habrá de guardar. Diego RAmirez DE VILLAEscusa, Constituciones synodales del obispado de Cuenca, Cuenca, 1531, ff. $5 \mathrm{v}$ 8r. Estas mismas disposiciones serán reiteradas por Fray Bernardo de FreSNEDA en slis Constituciones synodales de 1566, Madrid, 1571, f. 9v, asi como el obispo don Andrés PACHECo en sus Constituciones synodales de 1602, Cuenca, 1603, p. 78. 
Varias observaciones cabe hacer sobre esta ramificación jurisdiccional. Por un lado cabe interpretarla como un resultado de la imposibilidad de los prelados de hacerse cargo personalmente de todos los procesos judiciales que teóricamente debían ser resueltos por ellos. Hay que tener en cuenta el enorme espacio geográfico ocupado por la diócesis conquense, en la que llegó a haber más de trescientas parroquias, lo cual haría necesaria una distribución de las facultades jurisdiccionales. No obstante, hay que llamar también la atención sobre el hecho de que, debido a los excesos cometidos por los arciprestes y vicarios rurales en el ejercicio de su jurisdicción, a fines de la Edad Media los obispos conquenses tratasen de limitar la potestad jurisdiccional de estos últimos, lo cual iría encaminado a lograr un mayor grado de centralización en el ejercicio de la justicia episcopal. Por lo demás, esta existencia de varios niveles de jurisdicción eclesiástica dependientes de la del obispo era un fenómeno frecuente en todas las diócesis.

Cuando la justicia episcopal iniciaba algún tipo de proceso judicial, el primer paso consistía en citar a juicio a los encausados. De ello se solian encargar el portero y el pertiguero del obispo "segund costunbre antigua guardada en nuestra iglesia e obispado", citando a las partes y testigos a juicio a requerimiento del obispo o sus vicarios generales. A mediados del siglo XV sabemos que por cada persona a la que citasen cobraban un maravedí. En el sínodo de 1446 Fray Lope de Barrientos estableció que cuando el portero y el pertiguero estuviesen ausentes fuesen el provisor y vicarios del obispo los encargados de dar sus cartas con nombres y sellos para citar a los que debian ser llamados a juicio en la ciudad de Cuenca, cobrando por cada nombre o sello que diesen un maravedí. En el mismo sinodo también se mandó que los beneficiados de la catedral no pudiesen ser citados a juicio para fuera de la ciudad de Cuenca por carta de ningún juez ${ }^{10}$. Además, tanto en los juicios del obispo como en aquellos que se resolvian ante los vicarios y arciprestes rurales, también habia unos auxiliares llamados "nuncios" que se encargaban de llevar a su destino las cartas de citación, para lo cual tenían que recorrer a veces varias leguas de distancia, cobrando a cambio una pequeña remuneración económica en función de la distancia recorrida ${ }^{11}$.

En el sínodo de 1411 don Diego de Anaya, tratando de corregir una costumbre al parecer bastante extendida, mandó que nadie, clérigo o

10 Constituciones sinodales de 1446, f. $2 \mathrm{r}-\mathrm{v}$.

11 ACC, Libro de Estatutos, f. $62 \mathrm{r}$. 
seglar, pudiese citar más de una vez con una misma carta citatoria a la persona o personas en ella contenidas, sino que dicha carta, una vez empleada, pierda todo su vigor. También se estableció que la validez de dichas cartas citatorias fuese de cuatro meses a partir de su data, y que pasado dicho plazo carecerían de valor jurídico ${ }^{12}$.

Tiempo después Lope de Barrientos, en el sínodo de 1446, para tratar de evitar la usurpación de los derechos jurisdiccionales del obispo, mandaría además que toda persona de cualquier estado y condición que en adelante citase a alguien a juicio con alguna carta, debía declarar en ésta las causas por las que pretendía ejercer dicha jurisdicción y demostrarlo con títulos, ordenando también que en las cartas otorgadas por los jueces, vicarios y arciprestes se indicase siempre el nombre de la persona a la que se citaba a juicio, cosa que no siempre se hacía ${ }^{13}$.

Otra cuestión objeto de regulación fue la de los honorarios que tenían derecho a recibir los jueces, arciprestes, vicarios, notarios y escribanos por la labor desempeñada en los juicios. Para evitar que cobrasen cantidades mayores de aquellas que les correspondían, don Juan Cabeza de Vaca estableció por primera vez detalladamente en el sínodo de 1399 cuáles serían los honorarios que cobrarían por emitir sentencias en los juicios o participar en la expedición de los documentos. Se trata de cantidades que en general oscilan entre 1 y 12 mrs. para cada negocio particular, y según los casos es el vicario del obispo o su notario quien lleva la mayor parte. Por lo que respecta a los arciprestes y vicarios rurales y sus notarios o escribanos, se determina que cobren una tercera parte menos de lo indicado para los vicarios generales del obispo y sus notarios, prohibiéndose además que qualquiera de ellos reciba de manera oculta alguna cantidad de dinero extra por acuerdo con alguna de las partes en litigio, para de este modo evitar que se dieran sentencias amañadas ${ }^{14}$. Este mismo tipo de disposiciones serán reiteradas de nuevo por Lope de Barrientos en el sínodo de $1446^{15}$.

Hay que recordar también que, además de los honorarios cobrados de forma particular por todos estos oficiales de justicia, en ocasiones los obispos de Cuenca exigían del conjunto del clero el pago global de ciertas cantidades de dinero para costear el mantenimiento de los pleitos judiciales

\footnotetext{
lbid., f. $70 \mathrm{v}$.

Constituciones sinodales de 1446, ff. 6v-7r.

$\mathrm{ACC}$, Libro de Estatutos, ff. 33r-34r.

Constituciones sinodales de 1446, ff. 5r-6r.
} 
de diversa índole en que veia involucrada la Iglesia para defensa de sus intereses ${ }^{16}$.

La gravedad de la pena con que los jueces del obispo, vicarios o arciprestes castigaban a los culpables estaba en función del tipo de falta cometida, y podía ir desde el pago de alguna pequeña cantidad de maravedíes hasta la cárcel, privación de beneficios o excomunión, todo lo cual se encontraba legislado en las constituciones sinodales.

Sabemos que la cárcel del obispo de Cuenca estaba situada en algún lugar seguramente próximo a los palacios episcopales de la ciudad, y en ella eran recluídos los clérigos que habían cometido alguna falta grave que requeria tal castigo ${ }^{17}$, los cuales en ocasiones incluso acudían a la cárcel episcopal por iniciativa propia cuando en el delito cometido estaba involucrada también una parte laica, para de este modo ampararse en la jurisdicción eclesiástica frente a la secular que les era menos favorable.

Respecto a la forma de ejecutar las sentencias excomunión, se legisló ampliamente sobre ello en el sínodo celebrado por don Diego de Anaya en 1411. En esta asamblea el obispo mandó a todos los curas, clérigos parroquiales y sacristanes de la diócesis que hiciesen ejecutar cualquier sentencia de excomunión, suspensión o entredicho pronunciada por el obispo, deán, juez del palacio episcopal, vicarios generales y arciprestes de todo el obispado. Al parecer la clerecía diocesana era bastante remisa a la hora de hacer ejecutar dichas sentencias. Por ello el obispo establece que los clérigos parroquiales lean y publiquen las sentencias en sus iglesias y lugares próximos, registrándolas además en un libro en el que conste el tipo de sentencia de que se trata, quién la pronunció, dónde se leyó y cuándo, y contra quién va dirigida. En dichos libros también se recogerán las cartas de absolución que den los jueces y su fecha. De este modo se trataria de controlar a las personas sobre las que recaían dichas sentencias, evitando y prohibiéndoseles de este modo su asistencia a las iglesias durante la

${ }_{16}$ Asi, por ejemplo, en 1464 el obispo de Cuenca mandó repartir entre la clerecía de su diócesis el pago de $30.000 \mathrm{mrs}$., para la prosecución de los pleitos contra las personas que atentaban contra la Iglesia e inmunidad eclesiástica. El 3 de mayo de dicho año Alfonso Fernández, arcipreste de Cuenca, reconocería haber recibido de Martín Fernández, vicario de Cañete, los 1380 mrs., y medio que en dicho reparto tocó pagar a la villa de Cañete junto con la Tierra de Moya, Valdemeca y Villora. ACC, caj. 4 , leg. $15, n .^{\circ} 222$.

17 Dos ejemplos que pueden citarse sobre apresamiento de clérigos en la cárcel del obispo de Cuenca son los siguientes: Juan Canamero, clérigo de corona, el 7 de julio de 1421 (ACC, Actas Capitulares de 1421, f. 147r), y Francisco del Poyo, también clérigo coronado, el 3 de febrero de 1422 (ACC, Actas Capitulares de 1422, 1. 162v). 
celebración de los oficios divinos mientras no fuesen absueltos ${ }^{18}$. Este tipo de disposiciones también se repetirán en algunos sínodos posteriores, y la amplia utilización que a veces hicieron los jueces eclesiásticos de la sentencia de excomunión acabaría determinando una progresiva indiferencia de los fieles hacia sus consecuencias espirituales.

De la jurisdicción del obispo también se derivaba el derecho de éste o su vicario general a la colación de beneficios capitulares, parroquiales, capellanías y prestameras en Cuenca y su obispado, actividad en la que también intervenían el cabildo catedralicio, el papa y a veces los monarcas. De ahí que el obispo también pudiese privar de sus beneficios a los clérigos de su diócesis cuando éstos cometían algún tipo de falta grave que según las constituciones merecía tal castigo.

\section{Los sínodos diocesanos}

Los sínodos diocesanos eran reuniones del clero de una diócesis que, convocadas por el obispo, tenían como objeto hacer un balance sobre diversos aspectos concernientes al gobierno de la diócesis y controlar el comportamiento del clero y los laicos, corrigiendo los defectos e irregularidades existentes, a la vez que también constituian la más típica manifestación del poder jurisdiccional ejercido por el obispo.

Durante la Edad Media tenemos constancia documental de que en el obispado de Cuenca se celebraron al menos 16 sínodos diocesanos, 10 cual es muestra de una actividad sinodal importante si se compara con el número de sínodos medievales convocados en otras diócesis ${ }^{19}$. Casi todos estos sínodos se reunieron bien en la catedral conquense, o bien en el señorio episcopal de Pareja, y a ellos acudian, convocados por el obispo o su vicario general, todos los arciprestes y vicarios en representación del clero diocesano, bien personalmente o por medio de procuradores, asi como un importante número de miembros del cabildo catedralicio. Las constituciones emanadas del sinodo, que versaban sobre materias muy diversas, debían luego ser publicadas por todos los clérigos

is Archivo Histórico Nacional (AHN), Servicio Nacional de Microfilmes, rollo 14233.

19 Un grado de actividad sinodal parecido al de Cuenca se observa, por ejemplo, en diócesis como Oviedo, con un total de 15 sínodos celebrados durante la Edad Media, Mondoñedo, con 17, u Orense, con 19. Algo menos intensa fue la actividad sinodal en León, con 12 sinodos, Segovia, con 11, o Salamanca, con 10, mientras que Coria y Badajoz, con 5 sínodos para cada una de ellas, y Zamora, con tan sólo 2, resultaron mucho menos favorecidas en este sentido (datos tomados del Synodicon Hispanum, dir. por A. GaRcia y GaRCia). 
en sus parroquias los Domingos y días de fiesta, cuando estaba el pueblo reunido. De hecho en los sínodos conquenses se insiste reiteradamente en que todos los arciprestes, vicarios y curas tengan siempre a buen recaudo traslados fieles de las constituciones sinodales, cuyo incumplimiento se castigaba según la gravedad de la culpa con penas diversas que iban desde alguna pequeña cuantía de maravedíes hasta la prisión, privación de beneficios o incluso excomunión.

El primer sínodo sobre el que nos ha quedado constancia documental fue el reunido en Pareja por el obispo don Bernal Zafón en $1364{ }^{20}$. No obstante, en el texto de este sínodo se alude genéricamente a las constituciones que previamente habían sido promulgadas por algunos obispos anteriores "in diversis sinnodis per eos diversis temporibus celebratis" ${ }^{21}$, sin especificarse nada más sobre el particular, por lo que, en el hipotético caso de que la celebración de dichos sínodos anteriores hubiese tenido realmente lugar, resulta imposible determinar a qué sínodos se refiere.

El sínodo de 1364 fue convocado por el obispo don Bernal Zafón (1362-1372) y se celebró en Pareja, siendo publicadas las constituciones en el coro de la iglesia de Santa María de dicha villa el 11 de febrero del mencionado año, en presencia del deán de Cuenca Martín Fernández, algunos canónigos, vicarios y diversos procuradores del clero. La mayor parte de la normativa de este sínodo consiste en una especie de catecismo o manual para instrucción de clérigos y laicos, cuyos capítulos sobre preceptos religiosos están redactados en latín y a la vez traducidos al romance, para de este modo facilitar su comprensión al bajo clero y a la feligresía. Se establece que el capellán mayor de la Iglesia de Cuenca y los clérigos curados de la ciudad y diócesis publiquen dichos capítulos en las festividades de Navidad, Resurrección, Asunción de la Virgen y Todos los Santos, dándolas a conocer en lengua vulgar a sus parroquianos cuando estén todos reunidos. Siguen luego diversas disposiciones relativas al clero: normas sobre el vestido y adecentamiento personal, clérigos que permanecen durante largo tiempo excomulgados, ausencia de beneficiados en las parroquias, obligaciones sobre la celebración de la misa y el rezo de las horas canónicas, pago de la luctuosa, derecho de sepulturas en las iglesias, etc. En general se aprecia que se trata de unos estatutos sinodales dirigidos fundamentalmente hacia el clero, pues la normativa tocante a los laicos es escasa.

20 El texto original de este sinodo puede verse en: ACC, Libro de Estatutos, ff. $24 \mathrm{v}-30 \mathrm{v}$. Una copia del siglo xvill se encuentra recogida en: Biblioteca Nacional (BN), Ms. 13071, ff. $218 \mathrm{r}-239 \mathrm{r}$.

21 BN, 13071, f. $218 r$. 
Los siguientes sínodos con que nos encontramos son los celebrados por el obispo don Juan Cabeza de Vaca (1396-1407), durante cuyo pontificado tenemos constancia de la convocatoria de cinco reuniones de este tipo, que tuvieron lugar en 1399, 1402, 1403, 1404 y 1406, lo cual puede dar una clara idea de la preocupación de este prelado por la vigilancia y reforma de las costumbres del clero y laicos de la diócesis. Además, con estos sínodos nos situamos ya en el siglo XV que, para el conjunto de la Iglesia, representa uno de los momentos más intensos y típicos en cuanto a actividad reformadora, de la cual don Juan Cabeza de Vaca también se haría eco mediante la intensa actividad sinodal desarrollada en Cuenca.

El contenido general de todas las extensas constituciones emanadas de los sínodos celebrados por este prelado es enormemente amplio y variado, abordando la práctica totalidad de cuestiones susceptibles de ser tratadas en este tipo de reuniones eclesiásticas: administración y recaudación del diezmo, situaciones múltiples de conflictividad decimal, estado material y espiritual de las iglesias parroquiales, jurisdicción de arciprestes y vicarios rurales, cultura y comportamiento general del clero, aprendizaje de las virtudes y mandamientos básicos, vestimenta y apariencia externa clericales, mejoras en la celebración de la misa y administración de los sacramentos, concubinato clerical, excomunión, excesos de los laicos, usura, fiestas que se han de guardar, relaciones con los musulmanes y judíos, etc. Todo ello convierte a don Juan Cabeza de Vaca en uno de los prelados con mayor celo pastoral y preocupación por sus deberes estrictamente episcopales de todos aquellos que ocuparon la sede conquense durante la Edad Media, y de hecho las constituciones sinodales por él promulgadas se convertirán en la base fundamental de toda la producción sinodal conquense posterior. Veamos a continuación cómo y cuándo tuvo lugar la celebración de todos estos sínodos.

Al celebrar su primer sínodo como obispo de Cuenca, en 1399, don Juan se propuso reunir y reorganizar todas las constituciones dispersas dadas por sus antecesores, trasladando algunas del latín al romance "porque sean avidas comunes e usen dellas ansy los clerigos simples como los letrados", eliminando las que ya habían sido revocadas por otras posteriores y añadiendo otras nuevas elaboradas por él de nuevo cuño ${ }^{22}$, todas las cuales serían publicadas y leídas en sínodo el lunes 7 de abril de 1399, "estando el dicho sennor obispo asentado en pontifical dentro en la capilla de Corpore Christi, que es en la claustra de la su yglesia cathedral,

22 ACC, Libro de Estatutos, f. $31 \mathrm{v}$. 
celebrando la sancta sinodo". Estuvieron presentes el deản de Cuenca, don Guillén Barral; don Andrés Fernández, arcediano de Cuenca; don Alfonso Carrillo, arcediano de Moya; don Juan Rodríguez, chantre; don Pedro Fernández, maestrescuela; y don Miguel Fernández, tesorero, todos ellos dignidades de la catedral de Cuenca. También asistieron varios canónigos prebendados junto con todos los arciprestes y vicarios rurales y una amplia representación de la clerecía de Cuenca y su obispado.

En éste su primer sínodo como obispo de Cuenca, don Juan estableció que, conforme a los preceptos canónicos, en adelante se celebrase cada año en Cuenca un sínodo diocesano «en la Dominica de Quasimodo, salvo si nos mudaremos el dicho dia y lugar". A la convocatoria habrán de acudir el deán, canónigos o sus procuradores, arciprestes y vicarios rurales y dos clérigos de cada arciprestazgo y vicaría informados sobre el estado material y espiritual de sus parroquias. Además los arciprestes, vicarios y clérigos asistentes deberán llevar al obispo por escrito una relación con los nombres de todos los clérigos que poseen beneficios servideros, prestameras y capellanías perpetuas en sus respectivos arciprestazgos y vicarías, indicando también si existe algún beneficio vacante y quiénes están ausentes de sus beneficios ${ }^{23}$. De este modo quedaban establecidas las bases teóricas para épocas posteriores de la convocatoria y asistencia a sínodo, aunque, como pronto se verá, el precepto de convocatoria anual no se cumpliria.

El siguiente sínodo fue el celebrado en la parroquia de Santa María de Alcocer el lunes 3 de abril de 1402. Asistieron el deán don Guillén Barral; el chantre don Juan Rodríguez; el arcediano de Alarcón; los vicarios de Huete, Belmonte, Cañete y otros que no se citan; los arciprestes de Pareja, Moya, Uclés y otros clérigos en representación de los abades y cabildos clericales ${ }^{24}$. Al igual que hiciera en la reunión sinodal anterior, don Juan perdonó de forma general al clero muchas de las faltas tocantes a su jurisdicción en que habian incurrido ${ }^{25}$.

Al año siguiente, el 22 de abril de 1403, Domingo de Quasimodo, se celebraria un nuevo sínodo, en esta ocasión en la capilla de Corpore Christi de la catedral. Benito Sánchez de Salmerón, tesorero y vicario general, actuaría en nombre y con licencia del obispo don Juan, ausente por estar ocupado "de muchos negoçios açerca del serviçio de nuestro sennor

23 ACC, Libro de Estatutos, f. $32 \mathrm{r}$.

24 Ibid., ff. 50v-51r.

25 lbid., f. $54 \mathrm{v}$. 
el papa, e otrosi por quanto somos llamado por nuestro sennor el rrey". Acudieron los arciprestes, vicarios y una amplia representación de la clerecia, publicándose de nuevo las constituciones del sínodo de 1399, y la reunión continuaría al día siguiente, lunes 23 de abril, jornada en que la clerecía hizo varias peticiones al obispo sobre asuntos diversos ${ }^{26}$.

Otro nuevo sínodo fue el que se celebró también en la capilla de Corpore Christi, junto al claustro de la catedral, el miércoles 9 de abril de 1404, presidido, ahora sí, por el obispo don Juan en persona. Asistieron de nuevo don Guillén Barral, deán; el chantre don Juan Rodríguez; Benito Sánchez, tesorero; don Ruy Bernal, arcediano de Ledesma en la Iglesia de Salamanca; Gil Martinez, sochantre; el licenciado Ruy Diaz; varios canónigos de la catedral; los vicarios y arciprestes; el abad mayor del cabildo de clérigos de Cuenca y una amplia representación de la clerecia de la ciudad y del obispado. En este sinodo se publicaron de nuevo todas las constituciones dadas en los sínodos anteriores, algunas se modificaron en ciertos puntos, sobre todo en lo tocante a penas pecuniarias, y también se promulgaron nuevas contituciones emanadas de nuevo cuño ${ }^{27}$.

El último sínodo celebrado en Cuenca por don Juan Cabeza de Vaca se reunió también en la capilla de Corpore Christi de la catedral, entre el lunes 19 y el miércoles 21 de abril de 1406. De nuevo lo presidió don Juan vestido de pontifical, y contó con la asistencia del deán Guillén Barral, el chantre Juan Rodríguez, el tesorero Benito Sánchez de Salmerón, el licenciado Ruy Díaz, canónigos, arciprestes, vicarios, abades y varios clérigos de los cabildos de la diócesis. Se publicaron y leyeron las constituciones dadas en los sínodos anteriores, estableciéndose de nuevo los cambios oportunos ${ }^{28}$.

Casi tan intensa como la de su antecesor fue la actividad sinodal de don Diego de Anaya Maldonado (1407-1418), pues durante su pontificado en Cuenca convocó un total de cuatro sínodos, que se reunieron en $1409,1411,1413$ y $1414{ }^{29}$. El contenido de las constituciones de ellos emanadas es amplio, aunque no tanto como en el caso de los sínodos de su predecesor. De forma genérica, la temática tratada versa

26 Ibid., ff. $53 v-54$ r.

27 lbid., f. $55 \mathrm{v}$.

28 Ibid., f. 58 r.

29 Siendo obispo de Salamanca, don Diego ya había celebrado un sínodo en esta ciudad el 30 de enero de 1396. Se trata de una asamblea en cuya temática predomina la economia sobre el espiritu reformista, aunque contiene alguna normativa sobre enseñanza, sacramentos y culto. Juan C. MATiAs y VICENTE, Los laicos en los sinodos salmantinos, Salamanca, 1990, p. 18. El texto de este sínodo se encuentra publicado en el Synodicon Hispanum, IV, pp. 23-48. 
sobre los siguientes aspectos: mejora de la formación cultural del bajo clero, administración de los sacramentos, excesos diversos del clero, mejora del estado material y espiritual de las iglesias, excomunión, una no demasiado amplia normativa decimal, excesos de los laicos y algunas cuestiones tocantes a las relaciones de los cristianos con judios y musulmanes.

El primer sínodo de los convocados por el obispo don Diego se celebró el Domingo 14 de abril de 1409 en una capilla del palacio episcopal de Pareja. Asistieron don Ruy Bernal, arcediano de Ledesma y vicario general del obispo don Diego; el deán de Cuenca Guillén Barral; Pedro Fernández (de Montiel), maestrescuela y colector pontificio; arciprestes, vicarios, algunos clérigos y capellanes, bien personalmente o por medio de sus procuradores. En esta asamblea el obispo aprobó y confirmó las constituciones de don Juan Cabeza de Vaca, publicando además algunas nuevas dadas por él con acuerdo de todos los presentes ${ }^{30}$. Al día siguiente, en la línea de lo acecido en algunos sínodos anteriores, e! clero presentaría al obispo ciertas peticiones sobre temas diversos que habían sido tratados en la asamblea anterior ${ }^{31}$.

El siguiente sínodo se reunió ante el altar mayor de la catedral de Cuenca el lunes 14 de septiembre de 1411, tras la celebración de una misa solemne y cantada. Asistieron el deán Guillén Barral; el arcediano de Ledesma Ruy Bernal; algunos canónigos y racioneros de la catedral; seis arciprestes y cuatro vicarios, bien personalmente o por medio de procuradores; y una amplia representación de los abades y clérigos de los cabildos de Cuenca y su obispado. Tras una solemne predicación don Diego aprobó todas las constituciones anteriores, publicando además algunas nuevas y mandando a todos los presentes sacar una copia de ellas ${ }^{32}$.

Otro sínodo fue el celebrado en la parroquia de Santa Maria de Pareja el Domingo 17 de septiembre de 1413. Asistieron don Ruy Bernal, vicario general del obispo y arcediano de Ledesma; el maestrescuela Pedro Fernández; los arciprestes y vicarios de la diócesis, personaimente o por medio de procuradores; el abad del cabildo de clérigos de Alcantud, el procurador del cabildo de clérigos del común de Uclés, el abad del cabildo de Tierra de Moya, y otros abades y clérigos de la diócesis. Con el

\footnotetext{
3o ACC, Libro de Estatutos, f. $61 \mathrm{r}-\mathrm{v}$.

31 Ibid., f. $66 \mathrm{v}$.

32 ibid., ff. 68 r-72r.
} 
consenso de todos, se procedió a publicar ciertas constituciones sobre materia diversa ${ }^{33}$.

Por lo que respecta al último sínodo de don Diego de Anaya, celebrado en Pareja en 1414, así como al que convocó don Álvaro de Isorna (14181445 ) en 1424 , sólo puedo señalar que, tras vanos intentos, su consulta no me ha sido posible. No obstante, ello no impide que llegados a este punto pueda hacerse una apreciación importante, consistente en llamar la atención sobre el enorme contraste que se observa entre la intensa actividad sinodal desarrollada por don Juan Cabeza de Vaca y don Diego de Anaya, y la pobre labor que en este sentido llevó a cabo el prelado siguiente, don Álvaro de Isorna, y ello a pesar de los más de veinte años que duró su pontificado en Cuenca. Habrá que esperar la llegada de Lope de Barrientos a la sede conquense para encontrarnos de nuevo con una normativa sinodal de gran amplitud.

El primero y más importante de los dos sínodos celebrados por Fray Lope de Barrientos durante su pontificado en Cuenca (1445-1469) se reunió ante el altar mayor de la catedral el Domingo 19 de junio de 1446, después de celebrada misa solemne, y contó con la asistencia de Juan Alfonso de Oña, abad de Santiago y lugarteniente del deán Pedro Bocanegra; Juan Carrillo, arcediano de Cuenca; el chantre don Nuño Álvarez de Fuentencalada; don Ruy Gómez de Anaya, arcediano de Alarcón; Juan Sánchez de Loranca, abad de la Sey; el maestrescuela Álvaro de Jarava; Nicolás Martínez de la Campana, arcediano de Moya; varios canónigos y racioneros; los arciprestes de Cuenca, Huete, Uclés, Requena, y los lugartenientes de los arciprestes de Alarcón Castillo de Garcimuñoz, Moya y Pareja; los vicarios de Belmonte, Montalbo, Huerta, Cañete y lugartenientes de los de Iniesta y Utiel; diversos abades y clérigos representantes de los cabildos clericales de Cuenca y su obispado. Estando todos estos presentes se hizo predicación y lectura de las extensas constituciones de este sínodo con el objeto de mejorar las costumbres del clero y laicos de la diócesis ${ }^{34}$, estableciéndose que en adelante sólo se guardaran estas constituciones, que eran el resultado de una recopilación de las de sus predecesores con ciertos cambios y añadiduras ${ }^{35}$, y reiterando de nuevo las disposiciones del sínodo de don Juan Cabeza de Vaca de 1399 sobre obligatoriedad de asistencia al sínodo y convocatoria anual ${ }^{36}$.

33 Ibid., f. 72v.

34 Constituciones sinodales de 1446, t. 2 (preliminar).

35 Ibid., f. 1 r.

36 Ibid., f. $1 \mathrm{v}$. 
La temática tratada en las constituciones sinodales de 1446 es enormemente amplia, atañe al clero y en menor medida a los laicos, y es un reflejo de la preocupación del obispo por conocer y mejorar el estado material y espiritual de la diócesis cuyo gobierno se le acababa de encomendar. Entre los muchos aspectos sobre los que se legisló pueden destacarse los siguientes: materia económica y decimal, que recibe un tratamiento amplísimo; arrendamiento de bienes eclesiásticos; materia beneficial; asuntos jurisdiccionales, tanto de ámbito intraeclesiástico como en lo relativo a las intromisiones de la justicia secular en la eclesiástica; economía y administración parroquiales; inmunidad eclesiástica; regulación de las relaciones entre los diversos niveles del clero, así como entre éste y los laicos; relaciones de cristianos con judíos y musulmanes; aspectos de religiosidad referentes tanto al clero como a los laicos: concubinato, excesos de conducta, excomunión, administración de los sacramentos, fiestas, celebración de la misa, etc. ${ }^{37}$

Una vez leídas y publicadas las constituciones de este sínodo, todos los asistentes las consintieron y aprobaron. Finalmente don Lope mandó a todos los arciprestes, vicarios, clérigos y capellanes presentes que hiciesen sacar y se llevasen un traslado de estas constituciones así como de un Libro sinodal que el obispo presentó para mejorar la instrucción del clero diocesano conquense ${ }^{38}$. La temática de este Libro sinodal destinado al clero es esencialmente religiosa, y hoy sabemos que su elaboración original no es del propio Barrientos ${ }^{39}$, a pesar de lo cual éste consideró útil la promulgación de la obra en Cuenca para de este modo tratar de mejorar la formación y preparación intelectual del clero diocesano.

La segunda y última asamblea sinodal convocada por Barrientos de que tenemos constancia es la que se celebró en el altar mayor de la catedral de Cuenca los días 1 y 2 de mayo de 1457. La sesión del Domingo 1 de mayo se limitó a la celebración de una misa solemne, a la que acudieron el deán don Nicolás Martínez de la Campana; Juan Carrillo, arcediano de Cuenca; el chantre Nuño Álvarez de Fuentencalada; Ruy Gómez de Anaya, arcediano de Alarcón; Francisco Bordallo, abad de la Sey; Juan de Guzmán, abad de Santiago; bastantes canónigos y racioneros de Cuenca;

37 lbid., tf. 1-69.

38 Ibid., f. $68 \mathrm{v}$.

39 Biblioteca del Colegio de Santa Cruz de Valladolid, Ms. 340, ff. 71v-128r. Este Libro sinodal es copia del que otorgó el propio Barrientos para Segovia en 1440, que a su vez es copia del dado por el obispo de Salamanca Gonzalo de Alba en abril de 1410. Este último se encuentra publicado en el Synodicon Hispanum, IV, pp. 174-293. 
los arciprestes de Cuenca, Huete, Uclés, Alarcón, Castillo de Garcimuñoz, Pareja y los lugartenientes de los de Requena y Moya; los vicarios de Huerta, Iniesta, Montalbo y el lugarteniente del de Belmonte; cierto número de abades y clérigos de los cabildos del obispado. A esta misa el obispo don Lope no pudo asistir por estar «en sus palaçios de la dicha çibdad ocupado de otros arduos negoçios". Una vez finalizada su celebración todos los asistentes fueron convocados para el día siguiente por la mañana, para oir publicar y leer las constituciones del sínodo. De este modo, en la sesión del lunes día 2 de mayo primeramente se confirmaron y aprobaron las constituciones del sínodo de 1446, aunque corrigiendo algunas de ellas y publicando también otras nuevas, mandando finalmente que en el plazo de 60 días todos los arciprestes, vicarios y curas de la diócesis se hiciesen con una copia de las nuevas constituciones ${ }^{40}$.

La temática de las constituciones de este sínodo es mucho menos amplia que la del anterior, y las nuevas disposiciones dadas se limitan a recoger algunas normas muy puntuales sobre pago de diezmos, sentencias de excomunión, correcta administración de la justicia eclesiástica y deberes religiosos de clérigos y legos ${ }^{41}$.

Durante el pontificado de Antonio Jacobo de Veneris (1469-1479) no tenemos constancia de que se celebrara en Cuenca ningún sínodo, y ello fue debido probablemente al absentismo casi total de este prelado. No ocurrió lo mismo, en cambio, con su sucesor Fray Alonso de Burgos, que durante su breve pontificado en Cuenca (1482-1485) convocó dos sínodos ${ }^{42}$.

El primero de ellos se celebró el 13 de noviembre de 1482 en la villa episcopal de Pareja, presidido por el bachiller Alvar González de Capillas, provisor y vicario general en el obispado de Cuenca en nombre de Fray Alonso de Burgos. En este sínodo el mencionado provisor promulgó varias constituciones, algunas de ellas relativas a asuntos de tercerías ${ }^{43}$. Pero, indudablemente, la iniciativa de la convocatoria de este sínodo se debió a Fray Alonso de Burgos que, recién nombrado obispo de Cuenca, quiso

40 Sinodo de 1457, Biblioteca del Colegio de Santa Cruz de Valladolid. Ms. 340, ff. 129r$130 \mathrm{r}$.

41 tbid., ff. 129r-138r.

42 Sabemos que Fray Alonso de Burgos, siendo obispo de Córdoba (1477-1482), celebró alli un sínodo diocesano. También participó en la Asamblea del clero celebrada en Sevilla en 1478, siendo uno de los que la presidieron por parte del estamento eclesiástico. Su participación en estas reuniones es una muestra de la preocupación que este prelado mostró por los aspectos tocantes a la reforma eclesiástica, lo cual también quedaría patente poco después en el sínodo conquense de 1484 .

${ }_{43}$ Biblioteca del Real Monasterio de San Lorenzo de El Escorial, Ms. M.II.22, f. 2v. 
celebrar sínodo diocesano para conocer el estado de su nueva diócesis y, no pudiendo él asistir en persona, encargó a su vicario general que lo convocase en su nombre.

Dos años más tarde se celebró un nuevo sínodo en la villa de Pareja. Fray Alonso de Burgos, en el inicio de las constituciones sinodales de 1484, expresa su deseo de mejorar las costumbres de sus súbditos y corregir todos los defectos, tanto de los clérigos beneficiados de la catedral y resto de la diócesis como de los laicos, motivo por el cual había decidido reunir el sínodo. A su vez se lamenta de no poder visitar personalmente cada una de las parroquias de su diócesis "ansy por nuestra indispusiçion corporal como por la grandeza y numerosidat de los arduos negoçios que el rrey e rreyna nuestros sennores para la governaçion de sus rreynos e sennorios continuamente nos cometen..." ${ }^{44}$.

El sínodo fue convocado por Fray Alonso de Burgos en la villa episcopal de Pareja, donde se publicaron los estatutos sinodales el Domingo 17 de octubre de 1484. Asistieron el bachiller Rodrigo de Fuensalida, canónigo de Cuenca y visitador de la diócesis en nombre del obispo, los lugartenientes de los arciprestes del obispado, el vicario de Huerta, varios testigos y Francisco de Levera, notario apostólico y procurador del obispo ${ }^{45}$. Pocos días después, el 23 de octubre del mismo año, estos estatutos sinodales se publicaron de nuevo en la parroquia de San Nicolás de Medina, de la ciudad de Huete, en presencia del cabildo de clérigos de la ciudad, capellanes, el sacristán y varios testigos ${ }^{46}$.

Se establece que en adelante todas las parroquias tengan una copia de estas constituciones, y que cada cura parroquial las lea en alta y clara voz el primer Domingo de cada mes antes de vísperas, tañida la campana de la iglesia y reunido el pueblo ${ }^{47}$. Para facilitar esta tarea, poco después se encargará al tipógrafo Álvaro de Castro, que por esas fechas estaba establecido en la ciudad de Huete, que lleve las constituciones a la prensa, para posteriormente distribuir los ejemplares de la edición entre las parroquias de la diócesis ${ }^{48}$.

44 Constituciones sinodales de 1484, promulgadas por el obispo Fray Alonso de Burgos, f. 1r.

45 Constituciones sinodales de 1484, f. $15 \mathrm{v}$.

46 Ibid., f. $15 \mathrm{v}$.

47 lbid., f. 15r-v.

48 El único ejemplar incunable que ha llegado hasta nosotros de aquella prematura edición es el que actualmente se conserva en la British Library de Londres, con la signatura IB 53403. Un estudio pormenorizado y transcripción de estas constituciones sinodales puede verse en mi trabajo "Fray Alonso de Burgos y el sinodo conquense de 1484", Hispania Sacra, XLVII (1995), pp. 299. 346 . 
Respecto al tipo de temática recogida en estas constituciones sinodales puede decirse que es en general bastante similar a la tratada en los sínodos conquenses anteriores, y sus disposiciones normativas afectan tanto al clero como a los laicos. Entre los temas en ellas tratados cabria destacar los siguientes: formación cultural del bajo clero, concubinato y otros vicios clericales, obligaciones eclesiásticas del clero, cuidado y limpieza del material litúrgico de las iglesias, catequesis de los laicos, asistencia a misa y observancia de las fiestas de precepto, confesión y comunión, sentencias de excomunión, defensa del patrimonio eclesiástico, apuestas en el juego, cabildos de clérigos o laicos.

La última asamblea sinodal celebrada durante la Edad Media sobre la que nos ha quedado constancia documental es la que se reunió de nuevo en Pareja el 13 de noviembre de 1493, convocada por don Pedro de Costa, provisor y vicario general de la diócesis en nombre del cardenal y obispo de Cuenca Rafael Riario (1493-1518), que durante sus más de veinte años como titular de la sede conquense practicó un absentismo total y jamás se personó en esta diócesis. En nombre del cabildo catedralicio asistieron el arcediano de Cuenca, Gómez Ballo, y Ruy Gómez de Anaya, abad de Santiago, además de los arciprestes, vicarios, abades mayores de los cabildos, capellanes y otros clérigos. Debe llamarse la atención sobre el envío por parte del concejo conquense de dos regidores a este sínodo, con la misión de vigilar que no se hicieran innovaciones en materia decimal ${ }^{49}$. Por lo demás, la reunión no abordó una temática demasiado amplia, limitándose a la publicación de unas pocas constituciones y confirmación de otras anteriores ${ }^{50}$.

Finalmente, ya sólo queda poner de relieve la gran influencia que tendría toda esta producción sinodal de la Edad Media en los sínodos conquenses de los siglos posteriores. Durante el siglo XVI celebrarían sínodo don Diego Ramírez de Villaescusa, en 1531; Fray Bernardo de Fresneda, en 1566; don Gaspar de Quiroga, en 1574; y don Juan Fernández Badillo, en 1592. Para el siglo XVII pueden mencionarse los sínodos de don Andrés Pacheco, en 1602, y de don Enrique Pimentel, en 1626. Las constituciones sinodales emanadas de estas asambleas, aún cuando desde mediados del siglo XVI se haga sentir también en ellas el inevitable influjo de Trento, se basarán sobre todo en los sínodos conquenses bajomedievales, que de este modo sentarian muchas de las bases teóricas para el

50 Biblioteca del Colegio de Santa Cruz de Valladolid, Ms. 340, f. $69 \mathrm{v}$. 
posterior gobierno de la diócesis durante las centurias del Antiguo Régimen ${ }^{51}$.

\section{Derechos episcopales derivados del ejercicio de la potestad jurisdiccional}

\section{A) El catedrático}

El más representativo de estos derechos era el llamado impuesto del catedrático. El pago anual y forzoso de este tributo lo hacian los clérigos en reconocimiento del señorío exclusivo del obispo sobre ellos, y hasta tal punto era importante dicho pago que el obispo podía condicionar su intervención en defensa de los privilegios concu!cados a cualquier clérigo precisamente al pago de este tributo.

Esta imposición fiscal, cuyo valor aparte de económico venía a ser ante todo un símbolo del sometimiento del clero a la jurisdicción y señorío episcopal, ya se estableció en Cuenca desde muy poco después de la fundación de la diócesis, y a su pago anual estaban obligados todos los clérigos excepto las personas, canónigos, racioneros y compañeros del cabildo catedralicio. De gran importancia fueron en este sentido toda una serie de acuerdos que se establecieron el 7 de marzo de 1207, por mediación del obispo San Julián y con la aprobación de Alfonso VIII, entre el cabildo catedralicio de Cuenca y los clérigos parroquiales de la ciudad y sus aldeas, dado que entre estos acuerdos figura también uno relativo al modo como desde ese momento se habrá de realizar el pago del catedrático. A través de este importante acuerdo en primer lugar se rebajaron a dos los tres mencales anuales que pagaban los clérigos de la ciudad y sus aldeas al arcediano de Cuenca en concepto de catedrático, estableciéndose que si una parroquia no pudiese pagar dicha tributación debería asociarse a otra para tal fin. Respecto a los mencales que debía pagar cada clérigo al obispo por el catedrático, su número también se redujo de cinco que hasta entonces se pagaban a cuatro ${ }^{52}$.

\footnotetext{
51 Un claro ejemplo de ello nos lo ofrecen las constituciones del sínodo celebrado en mayo de 1626 en la catedral de Cuenca por el obispo don Enrique Pimentel. Para la redacción de estas constituciones sinodales se tuvieron en cuenta, tal como se reconoce en ellas, las de don Diego Ramirez de 1531, Fray Bernardo de Fresneda de 1571, y las medievales de don Juan Cabeza de Vaca de 1402 y de Fray Lope de Barrientos de 1446, entre otras.

$52 \mathrm{ACC}$, caj. $2, \mathrm{n} .^{\circ} 34 / \mathrm{AHN}$, Estado, leg. $3190, \mathrm{n} .^{\circ} 3$, ff. $20 \mathrm{r}-21 \mathrm{v}$. El mencal era una moneda de vellón usual durante el siglo xill en Castilla, equivalente a 18 pepiones.
} 
Algunos años más tarde, el 25 de abril de 1215, se realizaría un acuerdo de similares características entre el obispo de Cuenca don García y todos los clérigos de las aldeas de la Tierra de Huete, a través del cual éstos se comprometieron a entregar anualmente para el día de San Miguel por cada iglesia parroquial la cantidad de siete mencales "pacifice e sine fraude" "53 y el 23 de julio del mismo año don García realizaría un acuerdo muy parecido con los clérigos parroquiales de la propia villa de Huete, aunque en esta ocasión el número de mencales a entregar anualmente por cada iglesia para el día de San Miguel se vio reducido a cinco ${ }^{54}$.

En adelante el pago del catedrático seguiría siendo siempre forzoso, y habrá que esperar al sínodo celebrado por Fray Lope de Barrientos en 1446 para encontrarnos de nuevo con una legislación sobre el tema. En esta asamblea se reiteró de nuevo la exención de que disfrutaban las personas, canónigos, racioneros y compañeros del cabildo catedralicio con respecto al pago del catedrático. Por esta época, además, las cantidades de mencales antes citadas ya habían sido sustituídas hacía tiempo por los dos reales que debía pagar cada clérigo beneficiado y de orden sacra, y el real único con que debía contribuir cada clérigo no beneficiado. Esta cantidad se mantuvo, y además se estableció que los clérigos no beneficiados ni de orden sacra menores de 18 años no pagasen nada, excepto si sus padres o parientes se lo quisieran pagar. Los arciprestes y vicarios rurales habrian de encargarse de recoger dichos catedráticos hasta ocho días antes de la Pascua de "çinquesma" en los lugares de su jurisdicción, apuntando lo recaudado en un libro que se presentaría anualmente al obispo y pagando los maravedies recaudados al mayordomo episcopal en Cuenca dentro del término de los ocho días siguientes a la Pascua de "çinquesma» 55 .

Todas estas disposiciones sobre cantidad a pagar, personas exentas y forma de recaudación serán reiteradas por las constituciones sinodales de don Diego Ramírez de Villaescusa de 1531, en las que se insiste en que "antiguo derecho es que al prelado en cada diocesis paguen el cathedratico, que es renta devida en sennal y reconoscimiento de la cathedra

53 AHN, Servicio Nacional de Microfilmes, rollo 14227.

54 ACC, caj. 3, n. $^{\circ} 41$.

55 Constituciones sinodales de $1446, \mathrm{f} .37 \mathrm{v}$. Respecto a la cantidad con que debian contribuir para el pago del catedrático los clérigos de otras diócesis podría citarse, por ejemplo, el caso de Toledo, en cuya diócesis hacia 1354 este tributo forzoso consistía en el pago anual al arzobispo de la cantidad de 6 maravedíes por parte de la clerecía diocesana. José SÁnCHEz HerRERo, Concilios provinciales y sínodos toledados de los siglos XIV y XV. La religiosidad del clero y el pueblo, La Laguna, 1976, p. 110. 
pontifical» ${ }^{56}$. De este modo, durante las centurias del Antiguo Régimen aún se seguiría manteniendo esta forzosa tributación cuyos orígenes se remontaban al periodo fundacional de la diócesis, y que venía a ser un claro símbolo del reconocimiento de la autoridad episcopal por parte del clero diocesano.

\section{B) La luctuosa}

Otro tributo al que en un principio tuvieron derecho los obispos de Cuenca, pero cuyo pago pronto sería suprimido o sustituído por la entrega de una pequeña cantidad de dinero, fue el de la luctuosa. Esta tributación inicialmente consistió en la entrega a la mesa episcopal de una mula o rocín de montar y de un vaso, cifo o taza de plata de los bienes de cada canónigo o clérigo de la diócesis cuando tenía lugar la muerte de éstos. Respecto a su entrega por parte de los canónigos, el 18 de agosto de 1264 el obispo don Pedro Lorenzo realizaría un acuerdo sobre el particular con el cabildo catedralicio, en virtud del cual renunció a la mula y cifo de plata a que tenía derecho a la muerte de cada canónigo o racionero, a la vez que el cabildo renunciaba a la mula y copa de plata que tenía que recibir a la muerte de los obispos ${ }^{57}$. Pero además de esto, poco después, el 25 de noviembre del mismo año, don Pedro renunciaría de forma general, en su nombre y el de sus sucesores, al derecho de la luctuosa que sus antecesores venían cobrando de todos los clérigos de la diócesis, tachando esta costumbre de corruptela y calificándola de "irracionabili consuetudine" ${ }^{58}$.

La siguiente legislación que encontramos sobre el tema tuvo lugar en el sínodo celebrado por el obispo don Bernardo Zafón en 1364, en el cual se estableció que todos los arciprestes, vicarios y clérigos de la diócesis y ciudad de Cuenca que tuviesen beneficios entregasen en adelante a él y a sus sucesores la cantidad de $6 \mathrm{mrs}$. anuales como compensación del pago de la luctuosa del que quedaban exentos. Estos $6 \mathrm{mrs}$. se entregarian para la fiesta de San Andrés del mes de noviembre a los mayordomos y vicarios especialmente designados para esto por el obispo en cada arciprestazgo ${ }^{59}$.

56 Diego Ramirez de Villaescusa, Constifuciones synodales del obispado de Cuenca, ff. 33v-34r. Otras constituciones posteriores también seguirán insistiendo en la obligación de pagar el catedrático, tal como sucede en las Constituciones synodales de Fray Bernardo de FrESNEDA de 1566, f. $51 \mathrm{v}$.

57 ACC, caj. 7, n. ${ }^{\circ} 123$.

58 ACC, caj. $7, \mathrm{n},{ }^{\circ} 126 / \mathrm{BN}, \mathrm{Ms} .13071$, ff. $169 \mathrm{r}-170 \mathrm{r}$.

s9 BN, Ms. 13071 , ff. $235 r-236 r$. 
En el sínodo celebrado por don Juan Cabeza de Vaca en 1403 de nuevo se plantearía la cuestión, solicitando la clerecía al obispo que, tal como se venia haciendo desde antiguo, les librase del pago de la luctuosa o, en todo caso, si hubiesen de pagarla, les indicase cómo habría de efectuarse su pago que, respetando la "constitución antigua", debía consistir en la entrega de una mula, cama o taza de plata, o en su defecto 500 mrs. y no más ${ }^{60}$.

Al parecer fue esto último lo que se determinó, pues en el sínodo de 1409 el clero diocesano rogaría a don Diego de Anaya que excusase del pago de dichos $500 \mathrm{mrs}$. a todos aquellos clérigos que no fuesen concubinarios públicos, solicitando además al obispo que disminuyese la cantidad a pagar dado que muchos clérigos no podían hacer frente a su pago en la suma en que estaba tasada. Tras escuchar todas estas consideraciones don Diego acabaría accediendo a lo que le habían propuesto ${ }^{61}$. Éste es el último testimonio documental que se ha podido localizar referente a la luctuosa, por lo que nada más puede decirse respecto a la posible trayectoria seguida por su pago en épocas posteriores.

\section{C) Las procuraciones de visita}

El otro derecho económico importante de los obispos del cual se hablará a continuación eran las procuraciones de visita. Teóricamente, según la legislación canónica, todos los obispos debían visitar cada cierto tiempo las iglesias no exentas de su diócesis, directamente o, como fue más frecuente, mediante un representante de su jurisdicción, tarea por la cual se cobraban unas procuraciones de visita que no solian ser bien vistas por el clero. Las iglesias de patronato real no podian ser visitadas por el obispo, sino que las visitaba el rey o un representante suyo. Las líneas directrices a seguir en las visitas episcopales quedarian marcadas en el canon 13 del I Concilio de Lyon de $1245^{62}$.

6. ACC, Libro de Estatutos, f. $54 \mathrm{v}$.

b1 Ibid., f. 67r.

62 En este canon se aborda el problema fundamental de la conservación del patrimonio eclesiástico y de su correcta administración, cuya verificación se encomienda precisamente a las visitas de todas las iglesias a realizar. Se ordena hacer inventarios de bienes de iglesias, conventos y monasterios, que debian ser conservados cautelosamente. Importa ante todo el espíritu del canon, centrado en la defensa y administración de las propiedades y rentas eclesiásticas. Ch Hefele y H. LeCrero, Histoire des Conciles d'après les documents originaux, VI-1, Paris, 1914, pp. $649-651$. 
Para la Edad Media no se ha conservado ningún testimonio sobre visitas parroquiales realizadas personalmente por los obispos de Cuenca, pero sabemos que éstos, aunque no muy frecuentemente, en ocasiones las llevaron a cabo. No obstante, lo más frecuente fue que las visitas parroquiales las realizaran los arcedianos o vicarios en los que el obispo delegaba su jurisdicción para tal tarea. Estas visitas tenían como fin esencial supervisar el estado material y espiritual de todas las iglesias de la diócesis, mandando corregir las irregularidades encontradas, y por su realización los vicarios y oficiales visitadores cobraban de las rentas parroquiales ciertos derechos de procuración, cuestión esta última que en ocasiones daría lugar a que se produjeran airadas quejas contra el obispo y sus oficiales por parte del clero de la ciudad y diócesis, que consideraba abusivas dichas procuraciones.

El primer ejemplo de ello lo tenemos en 1221, durante el pontificado del obispo don García, y viene dado por un enfrentamiento que dicho año se produjo entre el obispo y el clero de la ciudad de Cuenca y sus aldeas, y que entre otras cosas estuvo motivado por la negativa de estos últimos al pago de los derechos de visitación del obispo, lo cual finalmente haría necesaria una intervención de Roma que dictaminó a favor del prelado conquense ${ }^{63}$.

En ocasiones posteriores la precariedad económica del bajo clero inclinaría a éste a tratar de eludir las visitas episcopales. Así, en el sínodo celebrado por don Juan Cabeza de Vaca en 1399, el clero diocesano solicitará al obispo que cese por ese año la visita de las parroquias, dado que estaban en muy mal estado a causa de la pobreza de la clerecía:

"Por quanto la vuestra clereçia del vuestro obispado esta pobre por los pechos grandes ansy realengos como eclesiasticos, pedimos vos por merçed que sea la vuestra merçed que çese la visitaçion vuestra y de los arçedianos este anno, porque se puedan rreparar para quando la vuestra merçed quisiere visitar..." ${ }^{64}$

El obispo don Juan accedió, así como a una petición similar de la clerecía que se repitió en el sínodo celebrado en Cuenca en 1403, año en que también se suprimieron las visitas del obispo y arcediano ${ }^{65}$. No obstante, el documento anterior es muy revelador en cuanto que denota la

63 AHN, Estado, leg. 3190, n..$^{\circ}$, ff. 33v-38r.

64 ACC, Libro de Estatutos, f. 49 r.

${ }_{55}$ lbid., f. $54 \mathrm{r}$-v. 
realización efectiva de visitas por parte de este prelado a las iglesias diocesanas durante algunos años de su pontificado, exceptuando por supuesto aquellos en que la visita fue suprimida.

No ocurriría lo mismo, en cambio, con alguno de sus sucesores, como por ejemplo Fray Alonso de Burgos, el cual en el inicio de las constituciones sinodales de 1484 se lamenta de no poder visitar personalmente cada una de las parroquias de su diócesis ${ }^{66}$. Un testimonio ya de época posterior sobre el tema de las procuraciones viene dado por las constituciones sinodales de 1531 promulgadas por el obispo don Diego Ramírez de Villaescusa, en las que se establece que todas las iglesias, hospitales y ermitas del obispado sean visitadas por lo menos una vez cada dos años por el obispo o personas comisionadas para ello por éste, mandándose además que si la iglesia visitada fuese tan pobre que no pudiese pagar la procuración, que en este caso el visitador reciba sólo una pequeña cantidad de ella o incluso nada ${ }^{67}$.

\section{D) Otros derechos}

Aparte de los derechos ya mencionados, que eran los fundamentales, los obispos de Cuenca también gozaron de otros en forma de tasas por la ejecución de la justicia episcopal, o bien por la colación de beneficios, expedición de documentos, pequeñas multas, etc. ${ }^{68}$ Pero el montante global de todas estas rentas debió de ser siempre bastante pequeño en relación a las rentas obtenidas por otras vías.

\section{Los señorios jurisdiccionales de los obispos de Cuenca}

Al igual que sucedió en otras diócesis, gracias a las donaciones regias del proceso de dotación inicial, durante el reinado de Alfonso VIII, los obispos de Cuenca pronto se convirtieron en dueños y señores de varios señoríos claramente jurisdiccionales en los que tenían potestad para ejercer la

Gi Constituciones sinodales de 1484, f. $1 \mathrm{r}$.

67 Diego Ramirez de VILlaescusa, Constituciones synodales..., f. 4r.

68 El 25 de febrero de 1350 el obispo don García concedería a todos los miembros del cabildo catedralicio exención del pago de derechos por la colación de beneficios así como por la expedición de documentos en la cancillería episcopal. ACC, siglo xIV, $n .^{\circ} 284$. En cambio el resto del clero de la diócesis seguiría obligado al pago de los mencionados derechos, lo cual viene a ser una clara muestra de la situación de privilegio ostentada por el cabildo catedralicio. 
justicia, y cuyos habitantes pasaron a ser vasallos episcopales obligados a pagar anualmente determinados tributos a su señor. Pero si bien los obispos de Cuenca eran los que en última instancia ostentaban la titularidad de estos señoríos, también es cierto que el cabildo catedralicio ejercía sobre ellos un cierto grado de potestad junto con el obispo pues, como ahora se dirá, el rey hizo estas donaciones al obispo e iglesia conquense. Veamos a continuación cómo tuvo lugar la formación inicial de estos dominios señoriales.

La primera donación regia, con la que además se inició el proceso de dotación de la nueva diócesis, tuvo lugar el 24 de febrero de 1182, y a través de ella Alfonso VIII donó al electo don Juan Yáñez y al futuro cabildo de canónigos los castillos de Peñas Alcatenas y Piedras Luches (Peralveche), situados en el extremo norte de la diócesis, junto al Tajo, con todas sus tierras y aldeas próximas para repoblar ${ }^{69}$. Sobre estos territorios los obispos de Cuenca tendrían derecho a ejercer en adelante un señorío territorial y también jurisdiccional, pues en el documento se indica que, con excepción del rey, nadie sino el obispo poseerá potestad alguna sobre esta donación: "ut nullus de cetero rex, nec dominus terre, nec merinus, nec aliquis alius homo habeat potestatem in ipsis".

Al año siguiente tendrán lugar otras dos importantes donaciones. La primera de ellas el 14 de noviembre de 1183, a través de la cual Alfonso VIII donó a don Juan Yáñez y a la Iglesia de Cuenca la aldea de Huerta con todos sus términos, para él y todos sus sucesores ${ }^{70}$. La siguiente tuvo lugar el 24 de diciembre, y en esta ocasión Alfonso VIII donó a don Juan y a su Iglesia la aldea de Abia, situada muy cerca de la anterior, con todos sus términos ${ }^{71}$.

Otra donación de señorio es la que nos encontramos el 12 de abril de 1187, y mediante ella Alfonso VIII entregó a la Iglesia de Cuenca y al obispo don Juan y sus sucesores los castillos de Monteagudo, con sus salinas y términos, y Paracuellos, con el portazgo sobre todos los ganados que pasasen por el castillo y sus términos ${ }^{72}$. La donación se hace sin duda pensando en su inmediata repoblación.

69 ACC, Libro de Estatutos, privil. VII, ff. $2 \mathrm{v}-3 \mathrm{r}$. Se trataba de un antiguo emplazamiento musulmán que había quedado desocupado ante el avance cristiano.

70 ACC, caj. $1, n .^{\circ} 6$. Se trata de una aldea de repoblación episcopal que había sufrido el abandono de sus pobladores cristianos ante una incursión almohade.

71 ACC, Libro de Estatutos, privil. $X, 1$. 3r. Se trata de una antigua aldea musulmana que habia sido abandonada ante el avance castellano. En torno a esta aldea los obispos de Cuenca llevarian a cabo una importante actividad repobladora, contando también para ello con la colaboración del concejo de Cuenca.

72 ACC, caj. $1, n .^{\circ} 10$. Tiempo después nos encontramos con otros privilegios relacionados 
El siguiente testimonio documental importante es ya algo posterior a los anteriores, pues data de 1198, y a través de él sabemos que entre esta fecha y la de la última donación antes mencionada la Iglesia de Cuenca había adquirido nuevos señoríos. De este modo, el $11 \mathrm{de}$ abril de dicho año 1198 Alfonso VIII confirmaría a la Iglesia de Cuenca y a su obispo San Julián la posesión de Pareja con sus aldeas (Parejuela, Chillarón, Halit, Trasfontanella y Tabradiella), así como la de Huerta, Abia, Monteagudo, Paracuellos y las heredades de Castillejo y Peantes ${ }^{73}$. En 1198 , por tanto, los obispos de Cuenca ya poseían un nuevo dominio, el de Pareja, que con el tiempo se convertiría en el señorío episcopal más importante de la diócesis. Así se cerraba la formación inicial de los señoríos de la Iglesia conquense.

Pero todas estas donaciones regias no obedecían simplemente a un deseo del monarca de dotar a la nueva Iglesia, sino que con ello Alfonso VIII también buscaba obtener de esta última una fuerte colaboración para una tarea de importancia capital en la política regia: la repoblación de las tierras recién conquistadas.

Geográficamente se distinguen varias zonas dentro de la diócesis en las que se pondría un especial cuidado para su repoblación por parte del obispo y cabildo catedralicio. Como zona más importante habría que destacar la margen izquierda del Tajo en el extremo noroccidental de la diócesis, teniendo como centros repobladores a Pareja y a los castillos de Peñas Alcatenas y Peralveche. La repoblación sería alentada por el monarca, y también a instancias de este último el concejo conquense colaboraría en la repoblación de esta zona. Así, si en 1198 obispo y cabildo habían iniciado la repoblación de Pareja, Chillarón y otras aldeas de la zona, desde ocho años antes el concejo de Cuenca se venía ocupando de las aldeas próximas de Mantiel, Cereceda, La Puerta, Viana, Solanilla, Peralveche, Arbeteta, Palomarejos y Huerta Vellida, que le habían sido donadas por Alfonso VIII para su repoblación el 17 de enero de $1190^{74}$. De este modo quedaba constituído uno de los principales núcleos repobladores de la diócesis. En segundo lugar destaca por su importancia

con las rentas a percibir en estos señorios. Así, el 25 de abril de 1220 Fernando III donará al obispo don García y a todos sus sucesores una renta anual de $300 \mathrm{mrs}$., en las salinas de Monteagudo: ACC, caj. $3, \mathrm{n} .{ }^{\circ} 46$, mientras que el 23 de septiembre de 1234 mandará de nuevo que se pague al obispo de Cuenca el portazgo del ganado que pase por el castillo de Paracuellos, sin duda debido a la reticencia que debia de existir a la hora de efectuar este pago: ACC, Libro de Estatutos, privil. LIV, f. 16r.

73 ACC, Libro de Estatutos, f. 3v.

74 Archivo Municipal de Cuenca, leg. 1, exp. 1. 
estratégica la repoblación de la zona meridional, en la que estarían como centros motores de toda la actividad repobladora los castillos del señorio episcopal de Paracuellos y Monteagudo. En esta zona también hubo cierta presencia repobladora del concejo conquense, dado que el 5 de septiembre de 1225 Fernando III confirmaría un deslinde de términos que se había hecho entre los pertenecientes al concejo de Cuenca, por un lado, y los pertenecientes a Monteagudo y Paracuellos, señoríos de la Iglesia, por otro ${ }^{75}$. Ya en último término tendríamos un centro repoblador de menor relieve que giraría en torno a las aldeas episcopales de Huerta y Abia.

Ante todo debe destacarse que desde un punto de vista jurídico es en torno a estos centros de repoblación donde los obispos consiguieron formar sus señoríos jurisdiccionales más importantes. Así, el rey, tratando de animar por todos los medios al obispo y su cabildo para que se integren en la actividad repobladora, les concedió los derechos más amplios en aquellos puntos cuya repoblación le interesaba desarrollar. Pero a pesar de todos estos esfuerzos la empresa repobladora no se vio coronada por un éxito pleno. Así, en 1257 aún continuaba la labor repobladora, pues dicho año el obispo don Mateo otorgaba una carta puebla a los nuevos pobladores del lugar de Vallermoso ${ }^{76}$. De todos estos señoríos episcopales, los castillos de Peñas Alcatenas y Peralveche a lo largo del siglo XIII irían cayendo en franco declive al perder la funcionalidad militar con que fueron creados. De este modo se explica el hecho de que el 1 de febrero de 1305 el obispo don Pascual junto con el cabildo catedralicio conquense realizasen un trueque con la infanta doña Blanca, hija del rey de Portugal, a

\footnotetext{
75 ACC, caj. 4, n. 59
}

76 El 19 de septiembre de 1257 el obispo don Mateo, con consentimiento del cabildo catedralicio, entregó a los pobladores de Vallehermoso la heredad que poseía en el cañizar de Yémeda y el Ero Hermoso, con la condición de que los que tuviesen dicha heredad le pagasen 40 mrs., alfonsies cada año. Los habitantes de Vallermoso que no disfrutasen de dicha heredad también deberían pechar al obispo en función de lo que tuviesen, y hacer todos los otros servicios que hacian al obispo los habitantes de los señorios de Paracuellos y Monteagudo. El nombre de Vallermoso (Valfermoso) le fue puesto a este nuevo pueblo por el propio obispo, el cual otorgó además a sus habitantes el Fuero de Cuenca según lo tenian los de Paracuellos y Monteagudo. En adelante todos los hornos y molinos que se construyesen en la villa y su término serian del obispo, estando además obligados sus habitantes a pagar siempre el diezmo «e que non ayan poder de dexar la heredat por razon ninguna". Por último se establece que ninguno de los nuevos pobladores pueda vender nada de su parte de heredad hasta pasados cinco años. ACC, caj. $6, n$. 103. El mismo dia en que fue emitido el documento anterior don Mateo concederá al cabildo catedralicio conquense parte de los mencionados $40 \mathrm{mrs}$., que habría de recibir el obispo con la condición de que el cabildo pusiese su sello en la carta puebla. ACC, caj. $6, n .^{\circ} 104$. No obstante, a pesar de todos los derechos que tendría el obispo en el lugar, lo cierto es que no acabaria constituyéndose en un auténtico señorio jurisdiccional, pues en la documentación de épocas posteriores nunca se le mencionará como tal. 
través del cual ésta recibió del obispo y cabildo el castillo de las Peñas de Viana (Peñas Alcatenas) que les había donado Alfonso VIII, haciendo entrega a cambio de la aldea de Gascoñuela, cerca de Alcocer ${ }^{77}$, en la cual el cabildo veía una mayor fuente de provecho.

El resto de los señoríos se mantendrían a lo largo de toda la Edad Media e incluso Antiguo Régimen, debiendo ser destacada la importancia prioritaria que pronto adquirió el señorío de Pareja ${ }^{78}$. También debe hacerse una referencia a otros dos señorios episcopales que aparecen documentados como tales desde fines del $\mathrm{XV}$, las pequeñas aldeas de Poveda y Vindel, sobre cuya formación no se ha conservado ningún dato. Aunque parece probable que fuesen adquiridas a través de alguna donación regia durante el proceso inicial de dotación, resulta imposible confirmar esta hipótesis ante la falta de información documental.

Tal como se acaba de señalar, Pareja pronto se convirtió en el más importante de los señoríos episcopales de la diócesis. En la villa los obispos tenían un palacio con una capilla donde se celebraban algunos oficios litúrgicos. Una clara muestra de esta importancia adquirida por Pareja lo constituye el hecho de que algunos sínodos diocesanos se celebraron en este lugar: así los de 1364 y 1413, en la parroquia de Santa María; el de 1409 en la capilla del palacio episcopal; y el de 1484, también celebrado en Pareja. Por otra parte, en la vecina aldea de Casasana los obispos de Cuenca tenían un castillo al menos a fines de la Edad Media. Esta temprana predilección episcopal hacia Pareja motivaría, entre otras cosas, que el 7 de octubre de 1255 Alfonso $X$, sin duda a instancias del obispo conquense, concediese a la villa la celebración de una feria anual durante los 15 días anteriores a la fiesta de la Cincuesma. A dicha feria podrian acudir para comprar y vender cuantos compradores de Castilla u otros reinos quisieran, tanto cristianos como musulmanes o judíos ${ }^{79}$.

En su señorío de Pareja, así como en el resto de los señoríos episcopales de la diócesis, los obispos de Cuenca, como señores, cobraban de sus vasallos toda una serie de derechos feudales que se venían a unir a las rentas de la mesa episcopal, y además intervenían junto con el cabildo

77 ACC, siglo XIV, n. ${ }^{\circ} 326 / \mathrm{AHN}$, Estado, leg. 3190, n. ${ }^{\circ}$, ff. 159r-160v.

78 Como recuerdo de la potestad señorial ejercida por los obispos de Cuenca en Pareja durante siglos, tras la supresión de dicha potestad en el siglo XIX los obispos de Cuenca aún seguirian añadiendo a sus títulos el simbólico de "señor de Pareja y Casasana", hasta que muy recientemente el obispo de Cuenca don Inocencio Rodríguez Diez decidiera suprimir definitivamente dicho título.

79 ACC, Libro de Estatutos, f. $16 \mathrm{v}$. 
catedralicio en el nombramiento de los oficiales concejiles y del alcaide de la fortaleza.

Sobre los derechos que cobraba el obispo nos han llegado algunos testimonios. Así, el 11 de julio de 1281 el obispo don Gonzalo realizaría un acuerdo con sus vasallos de Paracuellos a través del cual éstos habrían de pagarle cada año, por el pecho de San Miguel, el horno, la dehesa de conejos y por el molino del obispo en la hoz de Huércemes, $210 \mathrm{mrs}$. de la moneda blanca "que façen quinçe dineros blancos el maravedi", más quince pares de conejos con sus pieles. Esta cantidad a pagar sería fija, independientemente de que aumentase o disminuyese la población del lugar, y se entregaría anualmente en Cuenca al obispo o a su mayordomo. Además se establece que los ballesteros que moren en el lugar y maten venado estén exentos de pagar el pecho de San Miguel, mientras que los nuevos pobladores que acudan al lugar tampoco habrian de pagarlo en los tres primeros años. Por último se determina que el obispo mantendrá sus derechos de yantar, pedido y fonsadera ${ }^{80}$.

Sin duda todo ello constituía una notable fuente de ingresos para el mantenimiento de la institución episcopal, aunque de mucho menor relieve que la obtenida por otras vías, debiendo llamarse también la atención sobre las facilidades iniciales concedidas a los nuevos pobladores que acudiesen al lugar, poniéndose así de manifiesto el interés de los obispos por fomentar la repoblación de sus señorios. En algunos de ellos, además, los prelados retenían ciertos derechos especiales frente al concejo del lugar. Así sucedía por ejemplo en Pareja, donde el obispo de Cuenca tenía vedada para la pesca una parte del río ${ }^{81}$.

Aunque son de época mucho posterior, también resultan ilustrativos ciertos datos que sobre estas contribuciones señoriales nos ofrece el llamado Libro del Becerro de la Dignidad episcopal. Así, sabemos que en 1573 los concejos de Monteagudo y Paracuellos entregaban cada uno anualmente al obispo, para Pascua de Resurrección, 400 huevos, 4 ó 6 cabritos, dos carneros y dos cántaros de miel ${ }^{82}$.

Esta potestad señorial en ocasiones dio lugar a serios conflictos entre el obispo y sus vasallos, que consideraban injustos los abusos y nuevas imposiciones a que a veces se les sometía. El primer conflicto serio de que tenemos noticia se produjo en el siglo XIV, durante el pontificado del

ACC, caj. $11, n .{ }^{\circ} 191$.

Archivo Histórico Provincial de Cuenca, Desamortización, leg. 296, s.f.

Archivo Diocesano de Cuenca, Libro del Becerro de la Dignidad Episcopal, f. XLVIII. 
obispo don Garcia II (1342-1362), y la gravedad alcanzada por el asunto, dado que el obispo había ejecutado a bastantes de sus vasallos de Pareja y Casasana, hizo incluso necesaria la mediación pontificia ${ }^{83}$.

En la centuria siguiente, aunque sin revestir tanta gravedad, los conflictos serán constantes en todos los señorios fundamentalmente a partir del pontificado de Fray Lope de Barrientos, llegando hasta principios del siglo $X V I$, y estuvieron motivados por ciertos nuevos tributos que se exigieron a los vasallos: imposiciones de paja, leña, pan, peones, carros y bestias, posada al séquito del obispo, velas de las fortalezas, entre otras cosas ${ }^{84}$.

Por último, respecto al número de vecinos que habitaban estos señorios episcopales, carecemos de datos concretos para la Edad Media, pero sí que sabemos en cambio, gracias a una investigación mandada realizar con carácter general por Felipe 11 en todos los señoríos episcopales de Castilla, cuál era el número de vecinos en los señoríos conquenses hacia mediados del siglo XVI: Pareja y su Tierra, 534 vecinos; Monteagudo y Paracuellos, 172; Huerta y Abia, 119; Vindel, 62; Poveda, $53^{85}$.

\section{EL PATRIMONIO Y RENTAS DE LA MESA EPISCOPAL CONQUENSE. APROXIMACIÓN A SU ESTUDIO}

Es ésta una cuestión de suma importancia sobre la que, desafortunadamente, no es posible profundizar todo lo que sería de desear, y ello se debe fundamentalmente a que, en lo tocante a las rentas de la mesa episcopal conquense, y al igual que sucede con muchas otras diócesis castellanas, carecemos de relaciones de rentas y bienes tan amplias y detalladas como las que existen para la mesa capitular. Así, sólo es posible esbozar ligeramente, a partir de documentación muy dispersa, cuáles eran las rentas sobre las que se sustentaba la institución episcopal conquense durante la Edad Media.

En primer lugar hay que dejar bien claro que en Cuenca ya se dio desde un primer momento una división entre las mesas capitular y episcopal, cada una de las cuales tendría sus propias rentas. Prueba de ello es la dotación inicial de la mesa capitular que hizo el obispo don Juan Yáñez, primero en 1183, al crearse el cabildo, y más tarde en 1195.

83 Archivo Secreto del Vaticano (ASVat.), Reg. Vat. 145, ff. 220v-201r.

84 Archivo General de Simancas (AGS), Registro General del Sello, 29-1-1497, f. 305.

85 AGS, Patronato Real, libro de copias $n{ }^{\circ} 18$, ff. $337 \mathrm{v}-338 \mathrm{r}$. 
Desde luego, el diezmo se perfilaría muy pronto como la principal fuente de ingresos de la mesa episcopal. La distribución de los diezmos se realizaba según el sistema habitual en Castilla que consistía en su desglose por tercios que se repartian del siguiente modo: uno para el obispo y cabildo catedralicio, otro para el clero parroquial, y un último para la fábrica de los templos, del cual muy pronto se desglosarían a su vez dos tercios correspondientes a las tercias reales. No obstante, en Cuenca, ya desde un principio, se procedió a la división del territorio diocesano entre obispo y cabildo, de forma que cada uno tenía el derecho exclusivo a percibir el diezmo en los sectores geográficos que les correspondiesen, aunque a la norma general luego se sumaban multitud de excepciones que podían variar con el tiempo y contribuian a aumentar el extremado grado de complejidad que caracterizaba al fisco decimal en la diócesis conquense. Así, ciertos conceptos de ingreso se sometieron a criterios específicos de reparto, distintos del sistema general basado en tercios, y además cada cierto tiempo algunos productos podian experimentar cambios en las proporciones.

Tras los pasos iniciales, en el siglo XIV se habia llegado ya a una situación en que el obispo de Cuenca se reservaba el derecho a percibir el diezmo en Requena, Uclés - donde el cabildo también percibia una parte-, el sector de Iniesta, todo el arcedianato de Huete y las tierras del señorio episcopal ${ }^{86}$. El cabildo catedralicio, por su parte, percibia los diezmos en los arcedianatos de Alarcón, Moya y Cuenca, aunque en este último el obispo también retenía ciertos derechos. Este era el esquema general en el que, por supuesto, se daban muchas excepciones. A esto habría que añadir que, en las parroquias fundadas por la Orden de Santiago, y a raíz de toda una serie de acuerdos iniciales, el prior de Uclés retenia por lo general tres cuartas partes de los diezmos, proporción que también se solía dar en las iglesias propias fundadas por laicos. Además, la documentación también alude a transferencias a la mesa capitular hechas en ocasiones por los obispos de Cuenca de algunos prestimonios decimales pertenecientes hasta entonces a la mesa episcopal, lo cual generalmente se hacía con el fin de dotar mejor algún servicio litúrgico. En cuanto a las cantidades exactas percibidas por los obispos en razón del diezmo, para la Edad Media carecemos de cifras.

Otra fuente importante de ingresos de la mesa episcopal provenía de los señoríos jurisdiccionales que habían sido donados por Alfonso VIII y de

86 José María SánChez Benito, Las tierras de Cuenca y Huete en el siglo XIV. Historia económica, Universidad de Castilla-La Mancha, 1994, p. 213. 
los tributos que estaban obligados a satisfacer los vasallos. De todo ello ya hemos hablado en el apartado anterior.

Las salinas y, en menor medida, los portazgos, constituían otra fuente de renta. En cuanto a las primeras, la donación del castillo de Monteagudo realizada el 12 de abril de 1187 conllevaba también el diezmo de las salinas del lugar ${ }^{87}$, que los obispos de Cuenca percibirían hasta el 20 de octubre de 1297, fecha en que el obispo don Gonzalo Díaz Palomeque donaría al cabildo catedralicio, para dotación de las procesiones de los Domingos, los $500 \mathrm{mrs}$. anuales que hasta entonces percibía en los diezmos de dichas salinas ${ }^{88}$.

Pero los obispos de Cuenca también obtuvieron rentas de otras salinas. Así, el 25 de octubre de 1202, Alfonso VIII donaría conjuntamente al obispo y cabildo el diezmo de las salinas de Tragacete, situadas en la Sierra, próximas al nacimiento del Júcar ${ }^{89}$, y cuyo montante económico en los momentos iniciales debía ser importante. No obstante, parece ser que el obispo de Cuenca mantuvo durante muy poco tiempo su derecho sobre estas salinas, pues después Fernando III donaría enteramente al cabildo el diezmo de estas salinas de Tragacete, aunque su posesión por la institución capitular se perdería en el siglo XIV ${ }^{90}$.

Otra renta importante de sal concedida por Alfonso VIII, en este caso en exclusiva a la mesa episcopal, consistió en la donación, el 21 de julio de 1203 , de una renta de sal de 60 cahíces anuales en Medinaceli y su término ${ }^{91}$, debiendo destacarse que en esta ocasión se trata de rentas que quedan ya fuera del territorio de la diócesis conquense. Desconocemos durante cuánto tiempo mantuvieron los obispos conquenses su derecho a percibir esta renta de sal, aunque lo cierto es que en la documentación manejada las nuevas alusiones a esta renta en Medinaceli son prácticamente inexistentes.

Con todo, los obispos de Cuenca vieron en la sal un complemento importante a las rentas de su mesa, y ello explica que el 3 de abril de 1253

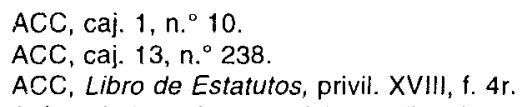

Asi se deduce de las peticiones dirigidas por el cabildo catedralicio de Cuenca a Enrique 11 probablemente en las Cortes de Toro de 1371, entre las cuales figura una queja exponiendo que en el momento presente habian perdido la posesión de las salinas de Tragacete que les había do. nado Fernando III, por lo cual solicitaban al monarca que les fuesen devueltas. ACC, siglo XIV, $n$. 288/BN, Ms. 13072, f. 131r.

${ }^{91}$ ACC, Libro de Estatutos, privil. XIX, ff. 4r-5V. 
Alfonso $X$, a petición del obispo don Mateo, concediese a éste un privilegio prohibiendo la entrada de sal en la diócesis ${ }^{92}$, lo que sin duda favorecería los intereses económicos del prelado y cabildo respecto a la sal.

En relación con esta importancia adquirida por la renta de la sal se encuentra un documento del 5 de agosto de 1257 por el que Alfonso X, a petición de los caballeros y "hombres buenos" del concejo conquense, que se quejaban de tener que pagar a la Iglesia el portazgo del ganado que pasase por el castillo de Paracuellos, concedería al obispo y cabildo conquense los pozos de agua para hacer sal en Valtablado, Valsalobre y Behamud, con cuatro yugadas de heredad, así como el derecho para poder vender la sal en todo el obispado, además de $600 \mathrm{mrs}$. sólo por ese año para que pudiesen poner en funcionamiento dichos pozos, todo ello a cambio de que en adelante no cobrasen portazgo al ganado que pasaba por el castillo de Paracuellos ${ }^{93}$. Ya en el siglo XIV, el cabildo entregaría a García Álvarez de Albornoz los pozos de Valsalobre y Beamud a cambio de una heredad en Arquillos y su término ${ }^{94}$.

En 1338, como es sabido, Alfonso XI promulgó un conocido ordenamiento en virtud del cual se reglamentaba la posesión para la Corona de las salinas, regulándose el monopolio regio de este producto. Lógicamente, la nueva disposición no dejó de tener consecuencias sobre la producción salinera de la diócesis conquense, al potenciar la intervención de la Monarquía y modificar algunos de los derechos que sobre ella se venían ejerciendo. En lo que toca al obispo de Cuenca, Alfonso XI reconocería en 1339 el pago anual a favor del prelado y cabildo catedralicio de 1200 mrs. sobre las salinas de Monteagudo, como compensación por antiguos derechos que al parecer habian sido cancelados sobre aquella salina ${ }^{95}$.

En definitiva, a pesar de todas las vicisitudes y cambios por las que pasó el derecho a percibir cierta renta de sal que tenían los prelados conquenses, lo cierto es que éstos siempre tuvieron en ella un complemento necesario a su economía, que defenderían durante el resto de la Edad Media al presentarse algún pleito relativo a su percepción.

Centrándonos ahora en el portazgo, los obispos de Cuenca no sólo estaban exentos de su pago, sino que también tuvieron concedido inicial-

32 José Manuel NIETO SORIA, “El equipamiento económico de una sede episcopal castellana de nueva creación: Cuenca, 1180-1280", Anuario de Estudios Medievales, 12 (1982), p. 320.

93 ACC, caj. 6, n. ${ }^{\circ} 101 / \mathrm{BN}, \mathrm{Ms} .13071, \mathrm{ff} .271 \mathrm{v}-275 \mathrm{r}$.

94 José Maria SÁnchez Benito, Las tierras de Cuenca y Huete..., p. 178.

95 José María SANCHEZ BENITO, op. cit., p. 179 
mente por la Monarquía su cobro en ciertos lugares. Así, el 7 de diciembre de 1200 Alfonso VIII confirmaría al obispo conquense su derecho para cobrar el portazgo del ganado que pasase por el castillo de Paracuellos hacia tierra de moros para ser vendido alli ${ }^{96}$. Hay que tener en cuenta que en esos momentos Paracuellos estaba muy próximo a la frontera musulmana. Además la importancia que para el obispo tenía el cobro de este portazgo, sobre el cual parece que el cabildo también tenía algún derecho, venia dada por el relieve cada vez mayor que alcanzaba la cañada conquense en el tráfico ganadero, siendo además Paracuellos un punto estratégico de paso hacia Valencia. No obstante, tal como se ha señalado antes, en 1257 el obispo perdería su derecho sobre dicho portazgo.

También en relación con la ganadería, parece ser que el obispo de Cuenca, al igua! que el maestre de Santiago, tuvo en ciertos momentos el privilegio de obligar a todos los campesinos y pastores sujetos a su jurisdicción a no vender la lana de sus ovejas a ningún mercader, debiendo entregarla a los recaudadores del obispo al precio que éstos establecieran, lo cual nos ilustra sobre el papel de la ganadería en la economía episcopal.

A lo dicho hasta ahora sobre salinas y portazgos habría añadir el privilegio que, el 10 de septiembre de 1195, fue concedido por Alfonso VIII conjuntamente al obispo y cabildo catedralicio, y a través del cual se les entregó el diezmo de todas las rentas reales en Cuenca, Huete, Valera, Monteagudo y Cañete. Sin duda es una de las donaciones más importantes de las otorgadas por el monarca, pues comprendía el diezmo de todas las salinas, portazgos, caloñas, quintos de las cabalgadas, de las labores de pan, vino, molinos, huertos, y de todas las otras cosas pertenecientes al rey en dichos lugares, excepto pedidos y fonsaderas ${ }^{97}$. Años más tarde, el 9 de septiembre de 1225, Fernando III confirmaría la donación anterior, trasladando además los portazgos de Cañete y Valera, respectivamente, a Moya y Alarcón ${ }^{98}$. Respecto a Moya, la explicación de este traslado viene dada por el hecho de que había sido repoblada a partir de 1210, adquiriendo pronto mucha mayor importancia que Cañete, que en 1225 era ya una aldea dependiente de Moya. Especial importancia tendría, además, el diezmo del portazgo que se cobraba en esta villa, dado el relieve ganadero de la comarca.

\footnotetext{
ACC, caj. 2, n. 29.

ACC, caj. 2, n. 24.

ACC, caj. 4, n. $^{\circ} 60$.
} 
Otra fuente de ingresos para la mesa episcopal, con carácter más bien complementario, vendría dada por los derechos que el obispo percibía en función de su potestad jurisdiccional: catedrático, procuraciones de visita, etc. Sobre todo ello ya se ha hablado páginas atrás. A ello habría que añadir, además, la parte que al obispo correspondía en las ofrendas y oblaciones que se realizaban en la catedral conquense.

De cara al afianzamiento del patrimonio de la mesa episcopal sería de fundamental importancia el privilegio concedido el 3 de abril de 1199 al obispo San Julián y sus sucesores, y también al cabildo catedralicio, para que pudiesen poseer todas aquellas heredades que adquiriesen por compra o donación en el territorio diocesano ${ }^{99}$. Así se les posibilitaba extender tanto como pudieran las posesiones abadengas, frente al retroceso inevitable que experimentarian las realengas.

Pero en cuanto a los bienes fundiarios que integraban la mesa episcopal tan sólo poseemos datos dispersos, la mayoría centrados en los momentos iniciales de la diócesis. Aparte de los señorios episcopales, de los que ya se ha hablado, los obispos de Cuenca poseían otros bienes, fundamentalmente rurales. El 14 de diciembre de 1208 Alfonso VIII había concedido conjuntamente al obispo don García y al cabildo catedralicio todas las posesiones reales en la hoz del Júcar, excepto molinos, además de los diezmos de las viñas de Alcocer, junto al río Guadiela ${ }^{100}$, aunque estos últimos se dejarían de poseer en tiempos de Alfonso $X$.

Tres años más tarde, el 6 de julio de 1211, el monarca castellano donará al obispo don García y sucesores cuatro yugadas de labor en el carrizal de Yémeda ${ }^{101}$, y el 21 de noviembre de 1214 confirmará a don García la donación del castillo de Paracuellos con todos sus términos, así como la heredad del carrizal de Yémeda y unos molinos situados entre Huércemes y el carrizal ${ }^{102}$. No mucho después, el 22 de enero de 1215, Enrique I donaría conjuntamente al obispo y cabildo una heredad en Noheda con ciertas aceñas en el Júcar, en las proximidades de Cuenca, para que con la décima parte de sus rentas se mantuviese una capellanía en el alcázar conquense, en la que se rezase por el alma de los padres del monarca ${ }^{103}$, aunque dos años más tarde el obispo don García donaría

99 ACC, caj. 2, ก. ${ }^{\circ}$ 26/BN, Ms. 13072, t. $22 \mathrm{r}-\mathrm{v}$.

100 ACC, caj. $2, n .^{\circ} 36$.

101 ACC, caj. 2, n. 39

102 ACC, caj. 2, n. ${ }^{\circ} 40$.

103 ACC, Libro de Estatutos, priv. XXV, 1. $5 \mathrm{v}$. 
al cabildo la parte que le correspondía en la heredad de Noheda, donación que entraría en vigor después de su muerte ${ }^{104}$.

A partir de este momento ya no volveremos a encontrarnos con ningún nuevo testimonio de donación de bienes raíces por parte de la Realeza a favor de la institución episcopal conquense, aunque, tal como hemos visto, sí que habría nuevas donaciones de rentas.

Apenas tenemos noticias sobre la presencia de bienes urbanos en la ciudad de Cuenca en el patrimonio de la mesa episcopal ${ }^{105}$, que debió de ser muy poco significativa, al contrario de lo que sucederia con el cabildo catedralicio, que consiguió formar un enorme patrimonio urbano en Cuenca. En lo que respecta a Huete, a raíz de una donación realizada el 3 de marzo de 1392 por el obispo don Álvaro Martínez a favor de sus sucesores en la mitra, la mesa episcopal vería aumentadas sus posesiones con varias casas y solares en la villa ${ }^{106}$.

Los obispos de Cuenca, al menos inicialmente, si que ejercian un importante control sobre los molinos hidráulicos, junto con el cabildo catedralicio y la Orden de Santiago. Así, a fines del siglo XIII sabemos que la institución episcopal conquense ya tenía la propiedad de al menos 8 molinos ${ }^{107}$. En cuanto a los siglos XIV y XV, no es posible establecer fehacientemente cómo evolucionó la posesión de molinos por parte del Episcopado, dado que casi todos los datos que tenemos se refieren a la institución capitular. Lo que sí parece cierto es que fue realmente el cabildo catedralicio quien ejerció un mayor control sobre los molinos hidráulicos, muchos de los cuales eran batanes, cuestión esta última que debe ser puesta en relación con el desarrollo experimentado por la industria textil en Cuenca.

Desde luego las donaciones de particulares jugarían un papel muy escaso, o nulo, en la formación del patrimonio episcopal, dado que en la inmensa mayoría de los casos los laicos dirigían sus donaciones al cabildo catedralicio a cambio del mantenimiento de capellanías y aniversarios.

Recapitulando, puede decirse que el diezmo fue, sin lugar a dudas, el principal sustento económico de la mesa episcopal. En segundo lugar ten-

104 ACC, caj. $3, n^{\circ} 46$.

105 En 1495 nos encontramos con una esporádica mención de ciertas casas censuales a la mesa episcopal en las que vivia un tal Gonzalo de Montealegre. Archivo Histórico Provincial de Cuenca, Desamortización, leg. 249, cuaderno de censos del cabildo, f. 8 r.

106 ACC, siglo XIV, $\mathrm{n} .^{\circ} 41$

107 Santiago AGUADÉ NiETO, "Molino hidráulico y sociedad en Cuenca durante la Edad Media (1177-1300)", Anuario de Estudios Medievales, 12 (1982), p. 269. 
dríamos las rentas procedentes de los señorios episcopales y otros bienes rurales propiedad de los prelados, debiendo destacarse la importancia inicial de los molinos hidráulicos. En cuanto al patrimonio urbano, parece que su presencia en la mesa episcopal fue mínima. En un nivel inferior tendriamos las rentas procedentes de los derechos del obispo sobre salinas y portazgos, aspecto sobre el cual, como hemos visto, hubo diversos cambios a lo largo del tiempo. Como complemento a todo lo anterior hay que citar el impuesto del catedrático que pagaba todos los años el clero diocesano, así como otros derechos derivados del ejercicio de la jurisdicción episcopal y parte de los donativos y oblaciones que realizaban los fieles en la catedral.

Al establecer una valoración global, aproximada, por supuesto, de las rentas episcopales de Cuenca a lo largo de la Edad Media, llama la atención el enorme y paulatino ascenso que experimentó la diócesis en su posición económica con respecto a otras. Así, el nivel de rentas episcopales durante los siglos XII y XIII, en una etapa de impulso inicial a la repoblación y economía diocesana, no debió de ser muy alto. En 1300, año del cual data el primer testimonio que ha llegado hasta nosotros sobre el pago de servicios comunes a la Cámara Apostólica por parte del obispo de Cuenca, sabemos que don Pascual se obligó a entregar la cantidad de 500 florines de oro ${ }^{108}$, cifra bastante baja que en aquel momento situaba a Cuenca entre las diócesis castellanas de escaso nivel económico, aunque también es cierto que las valoraciones establecidas en los documentos pontificios suelen tener un carácter más bien aproximado con respecto a los verdaderos niveles de renta episcopal. Pero, de manera orientativa, el dato es válido.

Poco después, en 1322, Juan XXII se reservaria el expolio del obispo don Pascual y los frutos de la mesa episcopal durante la vacante, que había durado dos años, por un importe total de 84.439 mrs. ${ }^{109}$ Hay que tener en cuenta que esta cifra, además de ser orientativa, incluye también el derecho de expolio y se refiere a las rentas episcopales durante dos años.

Mayor utilidad es la que quizá ofrece un documento ya posterior, del 15 de enero de 1479 , a través del cual sabemos que el obispo Antonio Jacobo de Veneris había arrendado al protonotario Gabriel

ios ASVat., Obl. et Solut., vol. 1, f. $11 \mathrm{v}$.

109 José GoÑ GaZTAMBIDE, "El fiscalismo pontificio en España en tiempo de Juan XXIIl", Anthologica Annua, 14 (1966), pp. 67-68. 
Condulmario, su provisor, los frutos de la mesa episcopal conquense por un valor de 4000 ducados anuales ${ }^{110}$. Claro que también es cierto que el valor del arrendamiento nunca coincidía de forma exacta con el valor real de las rentas arrendadas. Pero de manera orientativa el documento reviste interés. Además sabemos que en esta época el nivel de las rentas episcopales conquenses había experimentado una gran mejoría con respecto al siglo anterior. Ello lo demuestra el hecho de que en 1470 la Cámara Apostólica actualizase la cantidad a pagar por los obispos de Cuenca en concepto de servicios comunes, que quedaría fijada en 3000 florines de oro frente a los 500 que hasta entonces se pagaban ${ }^{111}$, lo cual situaba a Cuenca entre las diócesis con un nivel de rentas episcopales alto. Quizá ello explique el deseo pontificio durante esta época de entregar la mitra conquense a alguno de sus familiares y allegados, dado que el beneficio a recibir constituía un complemento económico cuantioso.

Ya para el siglo XVI, contamos con datos igualmente importantes que nos ilustran sobre la evolución de las rentas episcopales conquenses a lo largo de esta centuria. Así, Lucio Marineo Sículo, en su obra De rebus Hispaniae memoralibus, publicada en 1530, cifraba para ese año las rentas episcopales conquenses en 16.000 ducados, cantidad que situaba a Cuenca, por este concepto, entre las diócesis con un nivel de rentas medio-alto, tras Toledo, Sevilla, con 24.000, y Sigüenza, Santiago, Zaragoza y Burgos, todas ellas con $20.000^{112}$. En 1557 sus rentas ya habían ascendido a 26.000 ducados, y seguía manteniendo una posición económica de importancia, con unas rentas bastante similares a las de Sigüenza (25.000), Cartagena (24.000) o incluso Burgos (28.000) ${ }^{113}$. En el siglo siguiente esta situación de privilegio aún se mantendría, dado que en 1630 las rentas anuales de la mesa episcopal ascendían aproximadamente a 55.000 ducados, y las del conjunto de la diócesis conquense, excluído el clero regular, a 550.000. Así, en este año Cuenca también aparece entre las diócesis con mayor nivel de rentas de Castilla,

110 AGS, Registro General del Sello, 15-1-1479, f. 6.

111 ASVat., Obl. et Solut., vol. 84, 1. 110r. Tengamos en cuenta que el arzobispo de Toledo satisfacia 8000 florines, y si a ello unimos el enorme nivel de riqueza de la mitra toledana se llega a la conclusión de que los 3000 florines que correspondia a Cuenca son un claro indicativo de un nivel económico importante.

112 Santiago Aguadé Nieto, "Crisis de subsistencia, rentas eclesiásticas y caridad en la Castilla de la segunda mitad del siglo XV", En la España Medieval, 2 (1982), p. 31.

113 B. EsCANDEL BONET, "Las rentas episcopales en el siglo XV1", Anuario de Historia económica y social, 3 (1970), p. 68. 
pues por delante de ella sólo estaban Toledo, Sevilla, Santiago y Plasencia ${ }^{114}$.

Así, pues, partiendo de una situación económica inicial que se nos muestra como bastante precaria, el nivel de las rentas episcopales en Cuenca iría paulatinamente ascendiendo, de modo que, a fines del siglo $X V$, Cuenca ya se situaba entre las mitras con un nivel de rentas medioalto, manteniendo esta posición al menos durante los siglos XVI y XVII.

\section{LA PREEMINENCIA EPISCOPAL}

De todo lo dicho hasta ahora, puede inferirse con facilidad que el rango social que ostentaban los obispos en la ciudad de Cuenca se correspondía con el nivel más elevado de la oligarquía urbana. Ya en el Fuero de Cuenca se establece que no haya en la ciudad más que dos palacios, el del rey y el del obispo, mientras que el resto de las casas, tanto la del rico como la del pobre, la del noble como la del no noble, tendrán teóricamente los mismos derechos y las mismas obligaciones ${ }^{115}$. El palacio episcopal de Cuenca se situaría probablemente desde un primer momento en un lugar que aproximadamente se correspondería con el que ocupa en la actualidad, junto al lado derecho de la catedral. Además, al menos desde el siglo XIV, consta que los obispos de Cuenca poseian otro palacio en Huete ${ }^{116}$, asi como una capilla privada en esta villa, la de Santa Justa, que estaba situada cerca del postigo donde solía encontrarse su palacio ${ }^{117}$. A ello habría que añadir el palacio episcopal del señorio de Pareja, así como otras residencias y fortalezas que tenian los obispos en el resto de sus señorios.

Los símbolos principales de su elevada dignidad eran la mitra, el báculo y el anillo, que junto con la posesión de sello propio ${ }^{118}$ contribuian a real-

\footnotetext{
114 Quintín ALDEA, "La economía de las iglesias locales en la Edad Media y Moderna", Hispania Sacra, XXVI (1973), p. 23.

115 Fuero de Cuenca, edic de Altredo Valmaña Vicente, cap. 1, n. ${ }^{\circ} 8$, p. 41.

116 AHN, OOMM-Uclés, carp. 98, $\mathrm{n} .{ }^{\circ} 16$. Es un documento datado el 20 de septiembre de 1307 sobre un pleito entre el obispo de Cuenca don Pascual y el maestre de Santiago don Juan Osórez, motivado por un incendio del palacio episcopal de Huete acaecido mientras lo habitaban el comendador mayor de Segura, don Diego Muñiz, y otros caballeros santiaguistas.

117 Archivo Eclesiástico de Huete, Inventario, n. ${ }^{\circ}$. Se trata de un privilegio del obispo de Cuenca don Álvaro Martínez fechado el 4 de mayo de 1387, y en cual se alude a esta capilla de Santa Justa.

118 Los sellos que se conservan de los obispos de Cuenca tienen en general las características formales e iconográficas de los sellos episcopales de la época, apareciendo en ellos el prelado de
} 
zar el prestigio de su autoridad. Además el obispo, cuando participaba en las procesiones celebradas en la catedral, siempre ocupaba en ellas el lugar de máxima preeminencia, e igualmente destacado era su puesto en el coro y en las reuniones del cabildo. Por otra parte, cuando acaecía su fallecimiento y el sepelio tenía lugar en la catedral, siempre se le tributaban las máximas honras fúnebres en medio de un enorme cortejo que acompañaba sus restos mortales hasta el lugar de la inhumación, que en la catedral conquense solía tener lugar en el presbiterio o en algunas sepulturas situadas en el lado de la Epístola.

Acorde con el prestigio del obispo estaba también la posesión por parte de éste de ricas vestimentas y material litúrgico, necesario todo ello para el correcto desempeño de sus funciones eclesiásticas de una manera acorde

pie o sedente, en actitud de bendecir, revestido de pontifical y con los atributos simbólicos de su poder, como son la mitra y el báculo. No obstante, han llegado hasta nosotros algunos sellos de obispos conquenses que, debido a su particular riqueza iconográfica y simbólica, requieren una especial mención. Tal es el caso, por ejemplo, de un sello del obispo don Bernardo Zafón cuyo contenido iconográfico es el siguiente: templo gótico de dos cuerpos; en el superior la Virgen sedente, de $3 / 4$ a la derecha, velada y nimbada, con túnica y manto recogido sobre las rodillas y con el niño en brazos; a la altura de la cabeza de la Virgen aparece una estrella de ocho puntas; en los edículos laterales dos personajes separados por una fina columnita; en la parte inferior del campo, dentro de una hornacina, el obispo orante de $3 / 4$ a la izquierda; a ambos lados, un escudo de dos fajas (El sello se encuentra adherido a un documento del 1 de mayo de 1370 por el que se concede a Alvar López, racionero de Toledo, el arcedianato de Ledesma). Archivo Catedralicio de Toledo (ACT), 0.9.D.1.20/Luis ARoz PASCUAL, Sellos eclesiásticos del Archivo Catedral de Toledo (10991792). Estudio y Ccrpus descriptivo, Tesis Doctoral manuscrita, Toledo, 1984, II, p. 483. Del obispo don Álvaro Martínez también se conserva un sello de cera roja cuyo contenido reviste especial interés: templete gótico; en el centro la Virgen de pie, con velo, túnica y manto, y con el niño en el brazo izquierdo; en los edículos de la derecha e izquierda aparecen dos ángeles arodillados, con un cirial en las manos; en la parte inferior del campo, bajo un arco trilobulado, aparece el prelado orante con el báculo sobre el hombro; en los ángulos, dos escudetes, el de la derecha con creciente de luna renversado, y el de la izquierda con barra (Documento datado en Brihuega, a 7 de agosto de 1386. Es una concordia entre el arzobispo de Toledo y la abadesa y monjas de San Clemente sobre percepción de portazgo). ACT, V.11.G.1.6/L. AROz PASCUAL, op. cit., H, p. 485. Como último ejemplo cabria mencionar otro interesante sello de cera roja del obispo don Alonso de Burgos, ya del siglo $x v$, que se encuentra guardado dentro de una cajita de madera de pino y cuyos motivos iconográficos son los siguientes: retablo gótico; en el altar central aparece Cristo sedente, togado y con nimbo crucifero, y con la mano derecha levantada para bendecir; a sus lados, personajes indistintos; en la parte inferior del campo, bajo arco apuntado, aparece el prelado en pie y orante, acostado de dos escudos y timbrado de sombrero eclesiástico. (En un documento del 11 de abril de 1485, en Córdoba, que contiene el nombramiento del obispo de Cuenca para entender en las causas sobre conservación de bienes eclesiásticos del cardenal Pedro de Mendoza). ACT, I.5.C.1.16/L. AROz PAScual, op. cit., II, p. 486. Esta evolución en el contenido de los sellos episcopales, en los que desde el ultimo tercio del siglo XIV se tiende a que aparezca el prelado en actitud orante y rodeado de elementos propiamente espirituales, podria responder al influjo de las corrientes reformistas que abogaban por un modelo de prelado entregado a la pastoral y cumplidor de los deberes especificamente religiosos que le estaban encomendados, un reflejo de lo cual quedaria plasmado simbólicamente en los propios sellos episcopales. 
con la dignidad que ostentaba. Una valiosa información en este sentido es la que nos ofrece una carta de recibo que el 1 de junio de 1300 dio Sancho Ramiro, canónigo de Cuenca, a Juan Domínguez y Fernando Pérez, canónigos de Toledo, por los bienes que éstos le entregaron a nombre y por mandato del obispo de Cuenca don Pascual. La relación de bienes del ajuar del obispo que aparecen citados en ella es enormemente interesante:

\begin{abstract}
"Conviene a saber, una casulla, et dos almaticas, et dos tunicas de xamet bermeio; tres albas, las dos con aparaduras, et la una sin aparadura ninguna; quatro amitos, los tres con guarnimentos, et el uno sin guarnimento; una stola, et un amito de orofres fecho a imagines et labrado con aliofar; un cinto de orofres; dos capas de xamet bermeio; un par de sandalias obradas a leones et a castiellos con piedras con sus caizas de xamet bermeio; una mitra de xamet blanca con esmaltes et con piedras labradas con aliofar, et las piedras son ochenta e quatro entre chicas et grandes, et con su casa de fuste pintada; un peine de marfil; una croça de plata sobredorada sin [...]guno; unas façaleyas labradas de seda para delante los ynoios; un panno de seda con borlas paral sobrel fasçitol; una colcha pequenna de seda ahorrada en çendal verde et amariello; dos alquinas blancos de seda blanca con oriellas de seda verdes et bermeias; dos fazaleras de lino labradas de seda; otro par de fazaleras de lino obradas con filo cardenol; un faservelo con funda de seda viedro; et una arqueta pequenna en que son estas cosas: un ponfifical de oro con saphir grande con XVI pedrezuelas, et çinco sortijas de plata sobredorada con sus piedras ensartadas en una cordezuela, et otras nueve sortijas, et dos pontificales pequennos con sus pedrezuelas ensartadas en un panno et metidas en una luva blanca de seda, ef cinco pares de luvas obradas de seda, et dos cristiarios de marfil; una vestimienta para capellan con su alva et su camisa romana et estola et amito et manipulo et çinto; un sobrepelliz vieio et un frontal de seda; un caliz de plata con sus ampollas de plata; una cruzeta de plata sobredorada con piedras, con su pie de laton; una campaniella; un ara; un par de corporales con su funda; un misal; un evangelisterio et un pistolero; un offiçerio con canto; un ordinario con cubierta verde de parche; un ordinario de letra gorda con tablas de nogal; otro libro de consagraçion de los obispos de letra gorda con tablas cubiertas de cuero bermeio; otro libro de letra gorda de consagraçion de la crisma, cubierto de guadalmea bermeio; una Biblia con tablas de marfil et de evano con plata; un decreto glosado" 119
\end{abstract}

El obispo era auxiliado en el gobierno de la diócesis por el cabildo catedralicio, y además habia otra serie de oficiales que estaban a su servicio personal, entre los que pueden citarse el mayordomo, que se encargaba de la administración de las rentas de la mesa episcopal, el capellán priva-

119 ACT, X.1.E.2.1/BN, Ms. 13035, ff. 114-115. 
do, el camarero ${ }^{120}$ y el barbero ${ }^{121}$. Respecto al séquito que le acompañaba en sus desplazamientos, en general solía ser numeroso, pues ello era también una forma de realzar el prestigio de su dignidad.

Por último, la preeminencia social del obispo hacia que muchos clérigos quisieran entrar a formar parte de su círculo cercano de influencia, convirtiéndose de este modo en familiares del obispo y beneficiándose de las ventajas múltiples que ello podía conllevar. A este respecto resultan de interés algunas cartas de familiaridad otorgadas por los obispos de Cuenca que para el siglo XV han llegado hasta nosotros ${ }^{122}$.

Los obispos, en definitiva, ostentaban la máxima autoridad eclesiástica dentro de la diócesis y ello, unido a la enorme proyección social de su figura, que les situaba en nivel más elevado de la oligarquía urbana, hacia necesario el reforzamiento y realce de dicha autoridad con cuantos elementos y símbolos fuera posible.

\section{CONCLUSIÓN}

Durante las centurias medievales la sede episcopal conquense estuvo ocupada por un total de 31 prelados, desde don Juan Yáñez, que ya era electo en 1178, hasta el cardenal de San Jorge don Rafael Riario, obispo absentista entre 1493 y 1518. Los factores y circunstancias que incidieron en la designación de estos prelados fueron de lo más diversos y, junto a motivaciones estrictamente eclesiásticas, la mayoría de las veces serían mucho más determinantes factores de carácter político y social que estaban muy en relación con la propia dinámica evolutiva de la Iglesia occidental y con el desarrollo histórico de la Realeza y sociedad castellana. De este modo, en la elección de los obispos de Cuenca durante la Edad Media, junto al escaso papel que en la práctica, y sólo durante el siglo XIII, desempeñó el cabildo catedralicio, fue mucho más determinante el que jugaron la Monarquía castellana, el Papado y, en las etapas iniciales, los arzobispos de Toledo.

120 En un documento de octubre de 1417 nos encontramos a un tal Juan González de Frómista como canónigo y camarero del obispo de Cuenca. Archivo Municipal de Cuenca, leg. 185, exp. 1 .

12: En 1452 un personaje llamado Juan de Quirós aparece mencionado en la documentación como "barvero de nuestro sennor el obispo, su siervo". Archivo Histórico Provincial de Cuenca, Desamortización, leg. $782, \mathrm{n} \cdot{ }^{\circ} 831$.

${ }_{122}$ Puede citarse, por ejemplo, la carta que el 19 de abril de 1421 otorgó el obispo don Álvaro de Isorna a favor del arcediano de Cuenca Diego Martinez, tomándole por familiar y continuo co. mensal suyo. ACC, Actas Capitulares de 1421, f. 136v. 
La autoridad episcopal en el terreno eclesiástico quedaría plasmada en los tres tradicionales poderes del obispo que también ejercieron los prelados conquenses: poder de orden, poder de magisterio y poder de jurisdicción. De esta última potestad, la jurisdiccional, se derivaban algunos de los derechos del obispo sobre el clero diocesano, tales como las procuraciones de visita, el catedrático y la luctuosa. Los obispos de Cuenca legislaron en materia eclesiástica a través de diversos estatutos, que desde la segunda mitad del siglo XIV se promulgarian fundamentalmente en los sínodos diocesanos. Pero casi siempre fueron los vicarios generales del obispo quienes administraron justicia en su nombre, existiendo además, en un nivel inferior, la potestad jurisdiccional ejercida por el deán y los arcedianos, así como por los arciprestes y vicarios rurales y sus respectivos lugartenientes, en este último caso muy limitada.

Los sínodos diocesanos fueron la más clara manifestación del poder jurisdiccional ejercido por los obispos de Cuenca. Para la Edad Media hay constancia de que en el obispado conquense se celebraron al menos dieciséis sínodos, lo que muestra que hubo una actividad relevante en este sentido. Casi todos se reunieron en la catedral conquense o en el señorío de Pareja, y las constituciones de ellos emanadas versaron en su conjunto sobre la práctica totalidad de aspectos eclesiásticos, concernientes tanto al clero como a los laicos, susceptibles de ser objeto de legislación por el obispo.

Gracias a las donaciones regias del proceso de dotación inicial de la diócesis, durante el reinado de Alfonso VIII, los obispos de Cuenca pronto lograrian hacerse con algunos señoríos jurisdiccionales, cuyos habitantes y concejos pasaron a ser vasallos episcopales obligados a pagar anualmente determinados tributos en moneda y en especie al prelado, su señor. Estos señorios donados por el rey, sobre los que el cabildo catedralicio también ejercería un cierto grado de potestad, fueron los siguientes: los castillos de Peñas Alcatenas y Piedras Luches, que en el siglo xiv perderían importancia para la Iglesia conquense; las aldeas de Huerta y Abia; los castillos de Monteagudo y Paracuellos; y la villa de Pareja con sus aldeas, que pronto se convertiria en el principal señorío episcopal conquense. Gracias a estas donaciones, Alfonso VIII lograría la colaboración de los obispos de Cuenca en la repobiación de dichos lugares. Además, también existieron otros dos señoríos episcopales que aparecen documentados como tales desde fines del siglo $\mathrm{XV}$, las pequeñas aldeas de Poveda y $V$ indel, sobre las que se desconoce el momento exacto en que pasaron a ser señoríos de los obispos conquenses.

Finalmente, en lo que respecta al patrimonio y rentas de la mesa episcopal conquense, separada ya desde los momentos iniciales de la mesa 
capitular, los datos que han llegado hasta nosotros sobre la cuestión son francamente escasos. Desde luego, el diezmo pronto se perfiló como la principal fuente de ingresos de la mesa episcopal. Seguirían en importancia las rentas procedentes de los señoríos episcopales y otros bienes rurales propiedad de los prelados, debiendo destacarse el relieve inicial adquirido por los molinos hidráulicos. En un nivel inferior tendríamos las rentas sobre salinas y portazgos, que variaron a lo largo del tiempo. El complemento a todo lo anterior venía dado por el impuesto del catedrático que pagaba todos los años el clero diocesano, así como por otros derechos económicos derivados del ejercicio de la jurisdicción episcopal y parte de los donativos y oblaciones que realizaban los fieles en la catedral. En cuanto al patrimonio urbano de la mesa episcopal, parece que su importancia fue insignificante.

Estableciendo una valoración global aproximada sobre la evolución del nivel de rentas episcopales en Cuenca durante estos siglos, llama la atención el enorme y paulatino ascenso que experimentó la mitra conquense con respecto a otras a lo largo de la Baja Edad Media. Así, desde comienzos del siglo xiv el obispo de Cuenca debía pagar a la Cámara Apostólica 500 florines de oro en concepto de servicios comunes, cifra bastante baja que situaba a Cuenca entre las diócesis castellanas de renta poco elevada; en cambio, en 1470 la Cámara Apostólica actualizaría la cantidad que en adelante tendrían que pagar los prelados conquenses en concepto de servicios comunes, estableciéndose en 3000 florines de oro, lo que situaba a Cuenca entre las mitras con un nivel de rentas medio-alto. Hacia 1479, poco antes de morir, el obispo Antonio Jacobo de Veneris arrendaría a su provisor en Cuenca, el protonotario Gabriel Condulmario, los frutos de la mesa episcopal conquense por un valor de 4000 ducados anuales, lo que puede servir como dato orientativo del nivel de rentas de la mitra en esa época. $Y$ situándonos ya en el siglo XvI, cabe destacar que Lucio Marineo Sículo cifraba para el año 1530 las rentas episcopales conquenses en 16.000 ducados anuales, cantidad que situaba a Cuenca entre las mitras de nivel de rentas elevado, tras Toledo, Sevilla, Sigüenza, Santiago, Zaragoza y Burgos. 